\title{
Greenhouse Warming, Decadal Variability, or El Niño? An Attempt to Understand the Anomalous 1990s
}

\author{
M. LATIF \\ Max-Planck-Institute für Meteorologie, Hamburg, Germany \\ R. KLEEMAN \\ Bureau of Meteorology Research Centre, Melbourne, Victoria, Australia \\ C. ECKERT \\ Max-Planck-Institut für Meteorologie, Hamburg, Germany
}

(Manuscript received 21 September 1995, in final form 28 January 1997)

\begin{abstract}
The dominant variability modes in the Tropics are investigated and contrasted with the anomalous situation observed during the last few years. The prime quantity analyzed is anomalous sea surface temperature (SST) in the region $30^{\circ} \mathrm{S}-60^{\circ} \mathrm{N}$. Additionally, observed tropical surface wind stress fields were investigated. Further tropical atmospheric information was derived from a multidecadal run with an atmospheric general circulation model that was forced by the same SSTs. The tropical SST variability can be characterized by three modes: an interannual mode [the El Niño-Southern Oscillation (ENSO)], a decadal mode, and a trend or unresolved ultralow-frequency variability.

The dominant mode of SST variability is the ENSO mode. It is strongest in the eastern equatorial Pacific, but influences also the SSTs in other regions through atmospheric teleconnections, such as the Indian and North Pacific Oceans. The ENSO mode was strong during the 1980s, but it existed with very weak amplitude and short period after 1991. The second most energetic mode is characterized by considerable decadal variability. This decadal mode is connected with SST anomalies of the same sign in all three tropical oceans. The tropical Pacific signature of the decadal mode resembles closely that observed during the last few years and can be characterized by a horseshoe pattern, with strongest SST anomalies in the western equatorial Pacific, extending to the northeast and southeast into the subtropics. It is distinct from the ENSO mode, since it is not connected with any significant SST anomalies in the eastern equatorial Pacific, which is the ENSO key region. However, the impact of the decadal mode on the tropical climate resembles in many respects that of ENSO. In particular, the decadal mode is strongly linked to decadal rainfall fluctuations over northeastern Australia in the observations. It is shown that the anomalous 1990 s were dominated by the decadal mode.

Considerable SST variability can be attributed also to a linear trend or unresolved ultra-low-frequency variability. This trend that might be related to greenhouse warming is rather strong and positive in the Indian Ocean and western equatorial Pacific where it accounts for up to $30 \%$ of the total SST variability. Consistent with the increase of SST in the warm pool region, the trends over the tropical Pacific derived from both the observations and the model indicate a strengthening of the trade winds. This is inconsistent with the conditions observed during the 1990s. If the wind trends reflect greenhouse warming, it must be concluded that the anomalous 1990s are not caused by greenhouse warming.

Finally, hybrid coupled ocean-atmosphere model experiments were conducted in order to investigate the sensistivity of ENSO to the low-frequency changes induced by the decadal mode and the trend. The results indicate that ENSO is rather sensitive to these changes in the background conditions.
\end{abstract}

\section{Introduction}

The anomalous conditions during the 1990s were characterized by persistent large-scale positive SST

Corresponding author address: Dr. Mojib Latif, Max-Planck-Institut für Meteorologie, Bundesstraße 55, D-20146 Hamburg, Germany.

E-mail: latif@dkrz.de anomalies in the tropical Pacific and a weakening of the trade winds (Fig. 1). A detailed description of this unusual situation can be found, for instance, in Kleeman et al. (1996), Ji et al. (1996), Zhang et al. (1997), and Goddard and Graham (1997). The SST anomalies had serious negative climatic impacts on several regions, such as northeastern Australia, which suffered from a multiyear drought. The origin of this abnormal situation is still a matter of debate. Did we observe a "permanent" El Niño-a change in the mean state of the trop- 

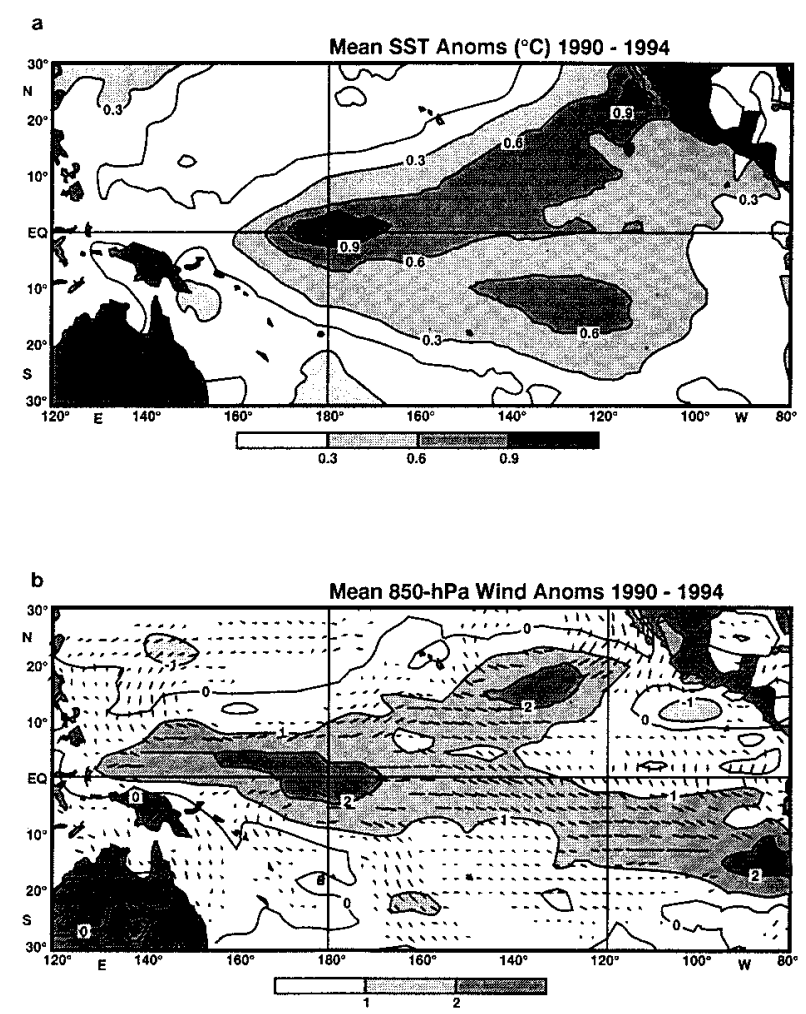

FIG. 1. (a) Mean SST anomalies observed during the period 199094 relative to the 1950-79 climatology and (b) associated mean lowlevel wind anomalies. Redrawn after Ji et al. (1996).

ical Pacific that is related to greenhouse warming-or simply an expression of decadal variability? As can be inferred from Fig. 1, the tropical Pacific SST anomaly shows aspects of ENSO (e.g., Rasmusson and Carpenter 1982), decadal variability (e.g., Graham 1994; Trenberth and Hurell 1994), and greenhouse gas induced warming (e.g., Meehl and Washington 1996).

The aim of our work is to provide an objective basis to discuss the most recent anomalous conditions. Our study is similar to the one by Barnett (1984), who tested several competing El Niño theories. In this study, we test the hypotheses put forward to explain the anomalous 1990s. We reanalyzed the tropical climate variability for the period 1949-94 for this purpose, in order to derive the fundamental modes of variability in the tropical climate system and to contrast them with the conditions observed during the last few years. Special emphasis is given to the dynamical consistensy of the different hypotheses with the conditions observed during recent years.

We follow an approach that involves both observations and model data. Observed SSTs are investigated in the first step, in order to derive the leading modes of tropical climate variability. The associated atmospheric anomalies are then derived from observations and, in a second step, from an atmospheric general circulation model (AGCM) forced by these SSTs. The AGCM pro- vides a consistent database for the whole time period, which could not be obtained by using observations only. A similar strategy using observed and model data was adopted by Graham (1995), who investigated the recent increase in global temperatures and the responsible physical processes. As will be shown below, we compared the simulated with the observed surface stress variations, and this comparison shows clearly that our model reproduces realistically the tropical climate variability.

We describe in section 2 the data, the statistical method, and the models used in this study. In section 3, we describe the fundamental modes of tropical climate variability. We discuss in section 4 the anomalous conditions observed during the 1990s in light of the variability modes identified. The hybrid coupled model results are presented in section 5 . The paper is concluded with a summary and discussion of our main findings in section 6 .

\section{Data, statistical method, and model descriptions}

\section{a. SST and rainfall observations}

The primary quantity analyzed is SST. It was taken from the GISST (Global Ice Sea Surface Temperature) (version 1.1) dataset (Parker et al. 1995), a development from the British meteorological service (UKMO) SST dataset (Bottmomley et al. 1990). The GISST dataset contains global SST data on a $1^{\circ} \times 1^{\circ}$ grid for the period 1949-91. We also used the SST dataset of Reynolds and Smith (1994), which was provided by the National Meteorological Center (NMC, now known as the National Centers for Environmental Prediction), covering the period 1982-94. The reasons for doing so are to get an indication of the differences between the two SST analyses and to extend the UKMO record. The NMC dataset is also global and provided on a $1^{\circ} \times 1^{\circ}$ grid. For use in this study, the SSTs were interpolated onto the Gaussian grid of our atmosphere model, which has a resolution of about $2.8^{\circ} \times 2.8^{\circ}$ (see below for further details). Although we are specifically interested in the Tropics, we analyzed the SSTs in the region $30^{\circ} \mathrm{S}-60^{\circ} \mathrm{N}$, in order to identify possible links to the midlatitudes of the Northern Hemisphere.

We also used rainfall observations from northeast Australia. This dataset was compiled from station data in the region $135^{\circ}-155^{\circ} \mathrm{E}$ and $11^{\circ}-26^{\circ} \mathrm{S}$.

\section{b. Statistical method}

Our statistical investigation of the SSTs is based on the method of "Principal Oscillation Patterns" (POPs), which is designed to extract the dominant modes of variability from a multidimensional dataset (Hasselmann 1988; von Storch et al. 1995). The POPs are the eigenvectors of the system matrix obtained by fitting the data to a multivariate first-order Markov process. POPs are, in general, complex with real part $p_{1}$ and 


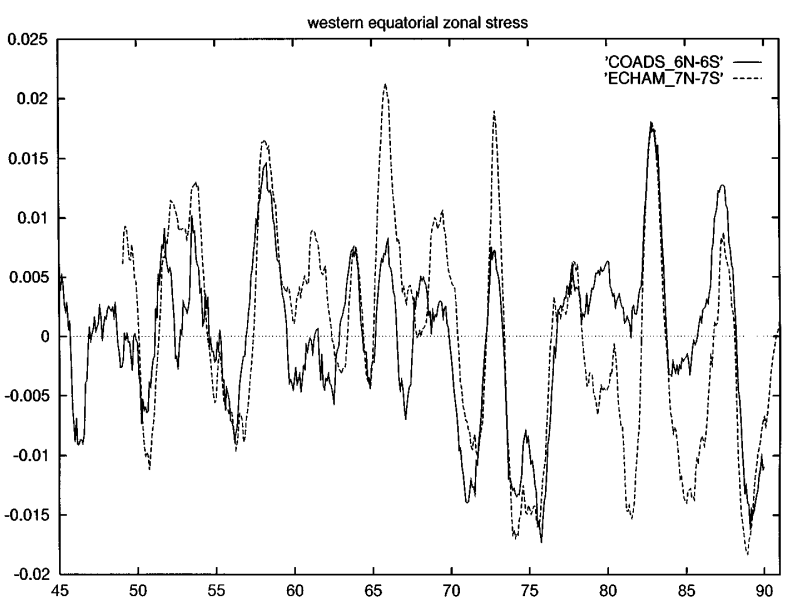

FIG. 2. Comparison of observed (full line) and simulated western equatorial zonal wind stress anomalies $(\mathrm{Pa})$.

imaginary part $p_{2}$. The corresponding complex POP coefficient time series, which are obtained by projection onto the adjoint POPs, satisfy the standard damped harmonic oscillator equation, so that the evolution of the system in the two-dimensional POP space can be interpreted as a cyclic sequence of spatial patterns:

$$
\cdots \rightarrow p_{1} \rightarrow-p_{2} \rightarrow-p_{1} \rightarrow p_{2} \rightarrow p_{1} \rightarrow \cdots
$$

The characteristic period to complete a full cycle will be referred to as the rotation period and the $e$-folding time for exponential decay as the damping time. The two timescales are estimated as part of the POP analysis. POPs can also be real. In this case, they respresent exponentially decaying modes. Additionally, associated regression patterns were computed from the observed stresses and the output of an AGCM driven with the observed SSTs by regressing the atmospheric fields onto the POP coefficient time series.

We investigated first the GISST SSTs, that is, the period 1949-91. The linear trend was removed prior to the POP analysis and is discussed separately. We obtained very similar results when we did not detrend the data prior to the POP analysis, the trend being described by a real POP mode. However, we felt more comfortable by removing the linear trend first for the sake of stationarity. The SST data were subjected to three additional manipulations prior to the POP analysis: The annual cycle was removed; the SSTs were smoothed applying a 5-month running mean filter and projected onto the first 10 EOFs accounting for about $65 \%$ of the total variance in the SST data.

The NMC SSTs were processed in the same way and then projected onto the leading two POP modes derived from the UKMO SSTs. This enables us to investigate the differences between the two SST datasets during the

a) linear trend in SST $\left[{ }^{\circ} \mathrm{C} /\right.$ decade], $1949-1991$

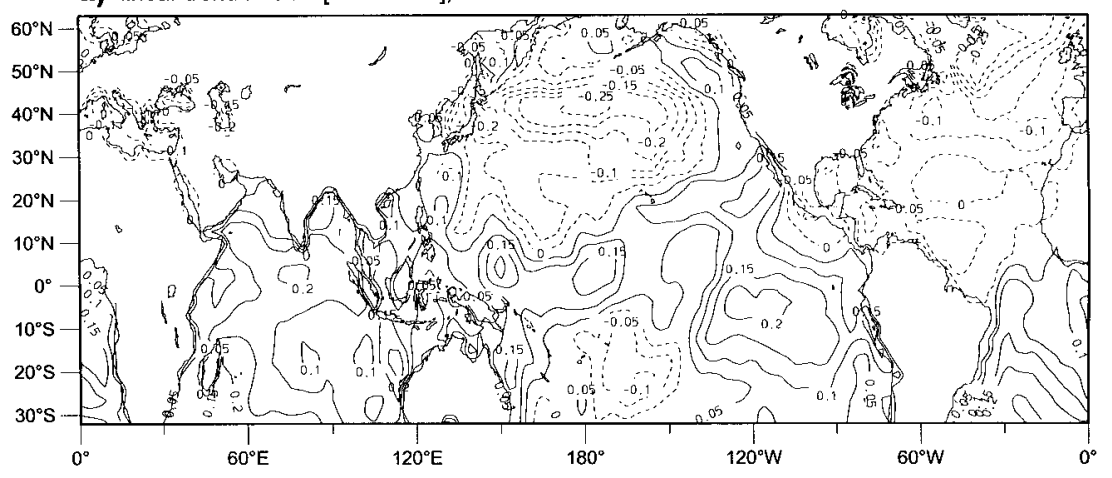

b) variance explained by the linear trend

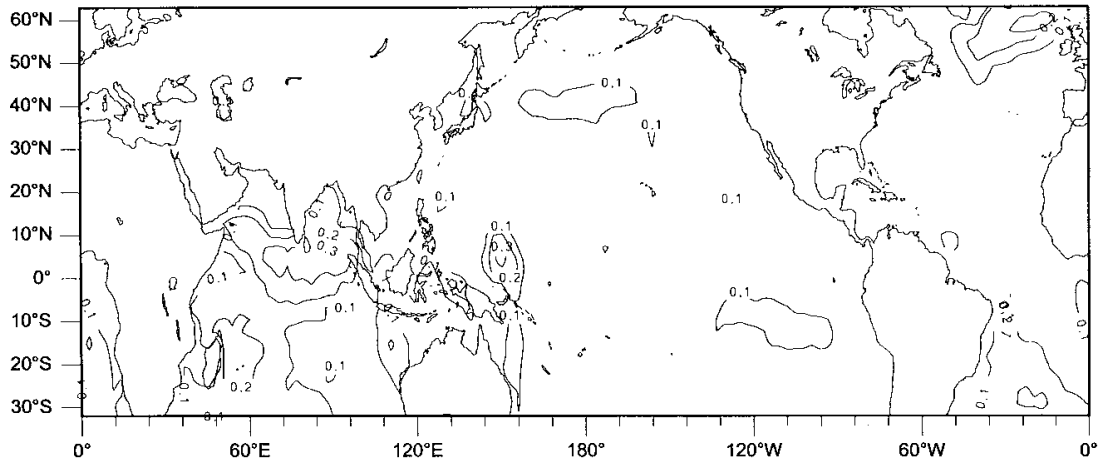

FIG. 3. (a) Spatial distribution of linear trend coefficients of SST $\left({ }^{\circ} \mathrm{C}\right.$ decade $\left.^{-1}\right)$ for the period 1949-91. (b) Variances explained in SST by the linear trends. 
a) linear trend in surface wind stress [mPa/decade], COADS

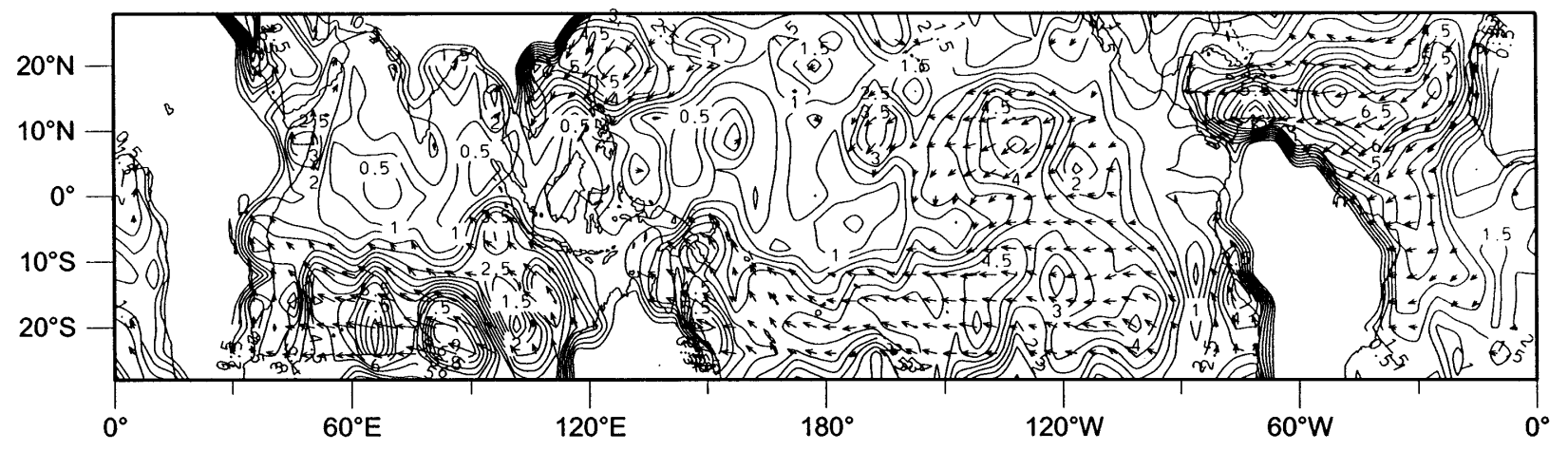

b) linear trend in surface wind stress [mPa/decade], ECHAM3

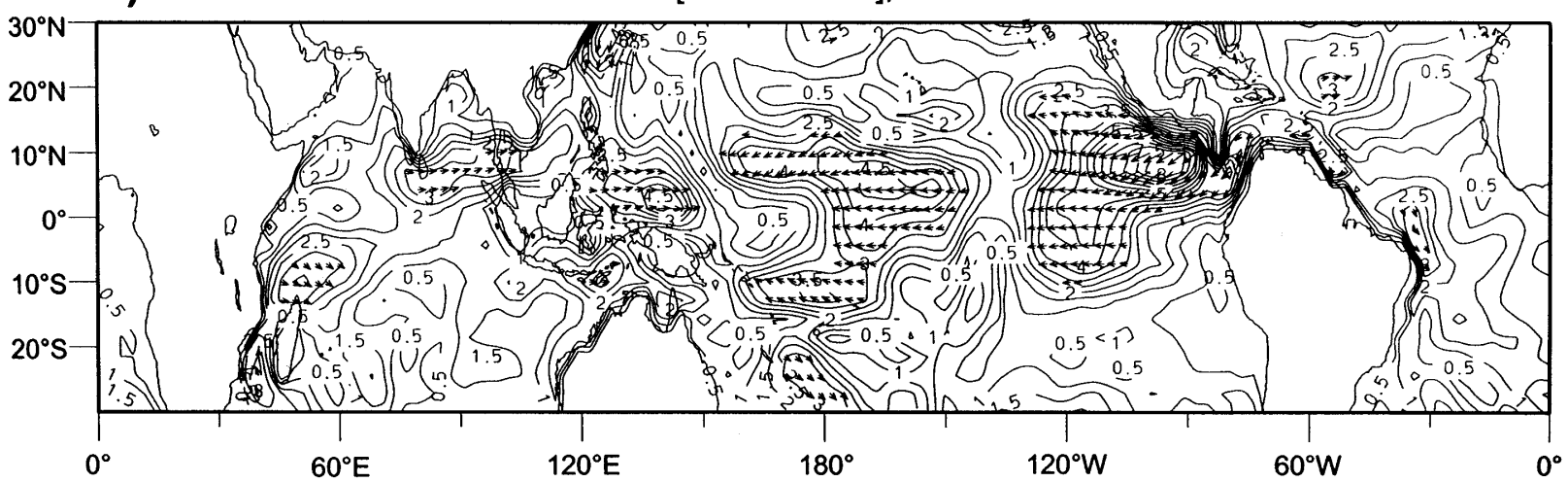

C) linear trend in sea level pressure [hPa/decade], ECHAM3

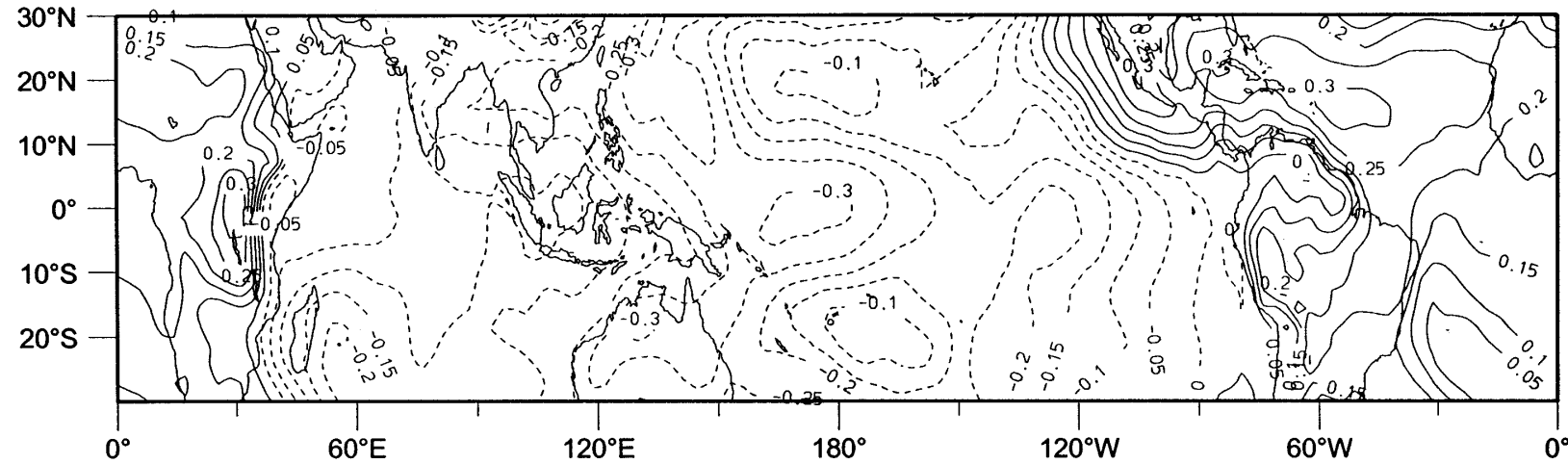

d) linear trend in precipitation [(mm/day)/decade], ECHAM3

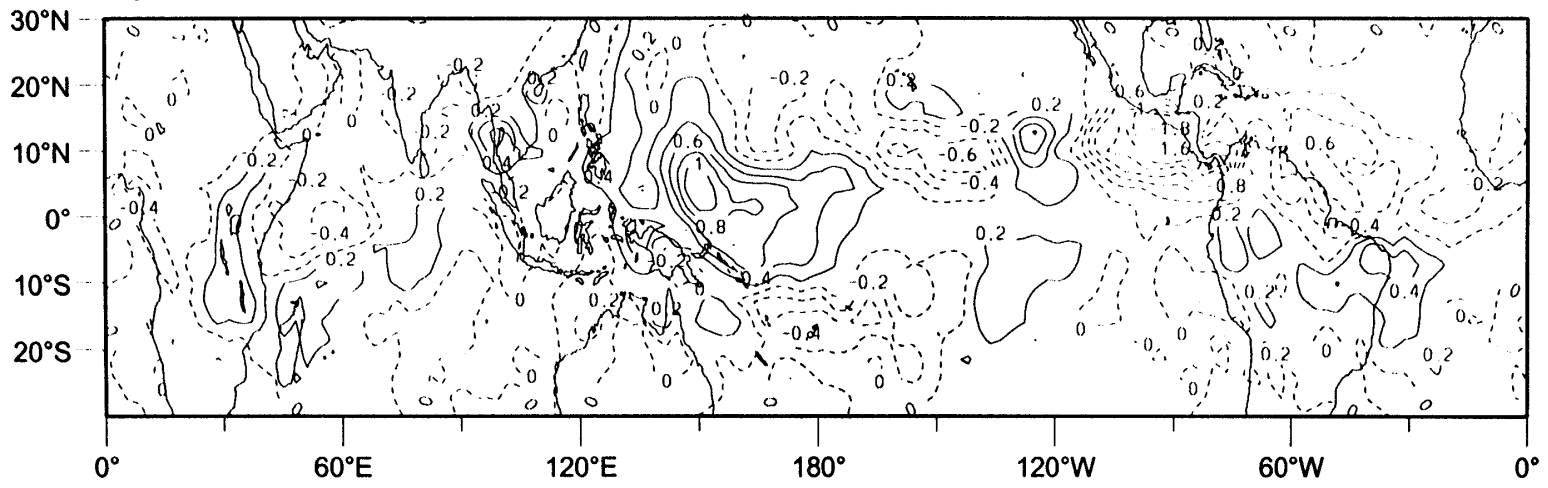


overlapping time period 1982-1991 and to extend our analysis of the anomalous 1990s to the end of 1994. In particular, we can compute "pseudo" principal components (PPCs) from the NMC SSTs that provide an objective measure of the strengths of the trend and the leading two POP modes during the 1990s.

\section{c. Observed surface stresses}

We derived the atmospheric fields that go along with the variability modes computed from the SSTs from both observations and a model simulation. Observed surface stresses were obtained from the dataset of da Silva et al. (1994), which was available for the period 1945-89. This dataset is an objective analysis of COADS onto a $1^{\circ} \times 1^{\circ}$ grid. We interpolated, however, the data onto a $5^{\circ} \times 4^{\circ}$ grid to do our analyses. Here, we use only the period 1949-89, which overlaps with both the SST (GISST) observations (1949-91) and the model simulation (1949-90).

\section{d. AGCM data}

We also used data from the output of our AGCM ECHAM-3, the Hamburg version of the European center operational weather forcasting model. The model is described in detail in two reports (Roeckner et al. 1992; DKRZ 1992). ECHAM-3 is a global low-order spectral model with a triangular truncation at wavenumber 42 (T42). The nonlinear terms and the parameterized physical processes are calculated on a $128 \times 64$ Gaussian grid, which yields a horizontal resolution of about $2.8^{\circ}$ $\times 2.8^{\circ}$. There are 19 levels in the vertical that are defined on $\sigma$ surfaces in the lower troposphere and on $p$ surfaces in the upper troposphere and in the stratosphere. ECHAM-3 was forced by the GISST SSTs for the period 1949-90, and we use here the surface wind stresses and sea level pressures from this run.

We shall use the model data only in the Tropics, since this region is strongly controlled by the SSTs (e.g., Lau 1985), so that multiple realizations are not necessary. The AGCM ECHAM-3 simulates realistically the tropical variability, as can be inferred from the paper of Stendel and Bengtsson (1996), who compared the recent observed tropospheric temperature changes with the corresponding model simulation. Here we show a comparison of the simulated with the observed zonal surface stress anomalies in the western equatorial Pacific, which is the most important region in our discussion, as described below (Fig. 2). The correlation between the observations and the simulation amounts to 0.7 . Thus, we believe that our atmosphere model is well suited to study tropical climate variability.

Both the observed stresses and the AGCM data were preprocessed in the same way as the SST data; that is, we removed the linear trend (which is discussed separately in section $3 \mathrm{a}$ ) and the annual cycle, and we smoothed them with a 5-month running mean filter.

\section{e. Hybrid coupled model}

The hybrid coupled model (HCM) used here is very similar to the model described by Barnett et al. (1993). It consists of an ocean general circulation model of the tropical Pacific coupled to a statistical atmosphere model. Details of the model and results of a number of sensitivity and prediction experiments can be found in Flügel (1994) and Fischer et al. (1997, manuscript submitted to Mon. Wea. Rev.). For the parameters chosen in this study, the HCM simulates a self-sustained and quasi-regular ENSO cycle, with a period of 5 yr. As shown in Barnett et al. (1993) and Flügel (1994) the space-time structure of the simulated ENSO cycle compares favorably well with observations, and the HCM's predictive skill in forecasting observed SST anomalies in the equatorial Pacific is rather high up to lead times of about $1 \mathrm{yr}$.

A series of $100-y r$ integrations was performed with the HCM, in order to study the sensitivity of the ENSO cycle to changes in the background conditions. For this purpose, low-frequency surface wind stress anomalies derived from the AGCM run forced by the observed SSTs were added to the model, which in turn introduce low-frequency changes in the three-dimensional density structure of the ocean. We restricted ourselves to investigate the impact of changes in the surface wind stress, since it is the most important forcing function for equatorial oceans. The associated changes in the surface heat flux are not considered.

\section{Variability modes}

\section{a. Trends}

We now turn to the description of the variability modes in the tropical climate system. We address first the linear trend in SST. This trend is a matter of intense scientific and public discussion, since it might reflect some aspects of SST changes associated with anthropogenic climate change. We note, however, that some regional features of the trend pattern are sensitive to the period considered. The SST trend pattern (Fig. 3a) shows, for instance, some aspects of the pattern of the

$\leftarrow$

FIG. 4. (a) Spatial distribution of linear trend coefficients of observed wind stress (mPa decade ${ }^{-1}$ ) for the period 1949-89. (b) Spatial distribution of linear trend coefficients of simulated wind stress (mPa decade ${ }^{-1}$ ) for the period 1949-90. (c) Spatial distribution of linear trend coefficients of simulated sea level pressure (hPa decade ${ }^{-1}$ ) for the period 1949-90. (d) Spatial distribution of linear trend coefficients of simulated precipitation $\left[\left(\mathrm{mm} \mathrm{day}^{-1}\right) /\right.$ decade $\left.)\right]$ for the period 1949-90. 


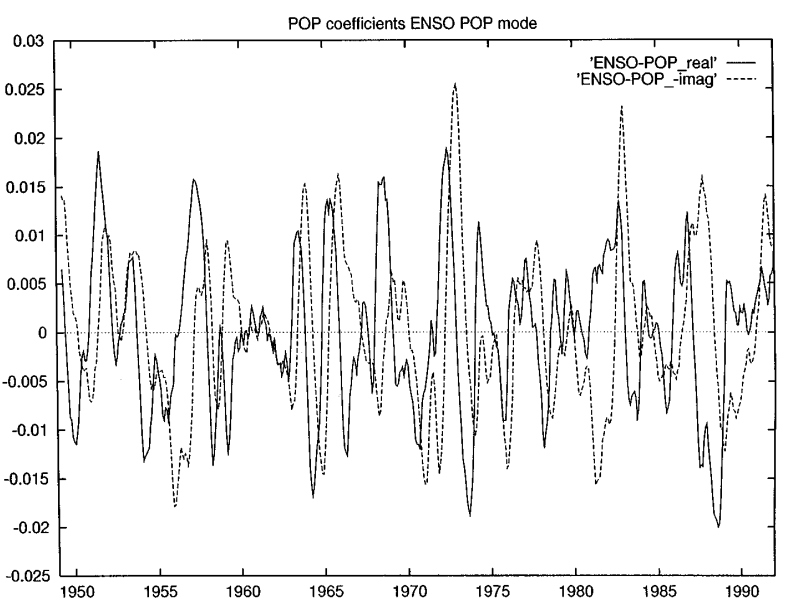

FIG. 5. POP coefficient time series of the ENSO POP mode. The real part is given by the full line, while the (negative) imaginary part is given by the dashed line.

third EOF shown by Parker and Folland (1991), who analyzed global SST fields for this century. In particular, Parker and Folland (1991) described the quasi-interhemispheric SST variations in the Atlantic, which are also found in the trend pattern. This, however, does not affect our conclusions, since we are mostly interested in the tropical Pacific.

The SST trend pattern shows some similarities to the anomalous conditions observed during the last years (Fig. 1) and to the warming pattern simulated by global coupled models in $\mathrm{CO}_{2}$-scenario runs (e.g., Hegerl et al. 1997, manuscript submitted to J. Climate; Murphy and Mitchell 1995; Meehl and Washington 1996). There is a clear tendency for all three equatorial regions to warm up, while parts of the subtropics and the midlatitudes of the Northern Hemisphere cool. Warming is also found along the west coast of North America, which is probably a response to the strengthened Aleutian low, as observed during the last decades (Meehl and Washington 1996) and the associated anomalous warm air advection. It is likely that the cooling in the North Pacific is also related to the intensified Aleutian low (e.g., Namias 1963; Cayan 1992, Wallace et al. 1990; Wallace et al. 1996). A deepened Aleutian low is accompanied by enhanced westerlies, which will lead to reduced Ekman heat transport, enhanced oceanic mixing, and stronger oceanic heat loss. All three processes will tend to cool the ocean, consistent with the model study of Miller et al. (1994).

The variances explained by the linear trend are relatively high in the Indian Ocean and far western equatorial Pacific (Fig. 3b), with maximum explained variances of about $30 \%$ near the equator south of India relative to the raw monthly anomalies. Thus, a considerable part of the warm pool region has warmed significantly at a rate of at least $0.1^{\circ} \mathrm{C}$ per decade. The trends in the eastern tropical Pacific are relatively small and do not account for much variance. Thus, the SST gradient along the Pacific equator is enhanced, and this can have important implications for the Walker circulation over the Pacific, as described below. Two other regions of relatively high explained variances are found. The first is located in the North Atlantic, which cooled considerably, while the second is found in the subtropical Atlantic of the Southern Hemisphere, which shows a relatively strong warming tendency.

We computed then the linear trends from the observed surface stresses (Fig. 4a). Of particular importance here is the tropical Pacific, which shows a strengthening of the trade winds. Anomalous convergence is found in the equatorial Pacific near the date line. The trends in the surface wind stress as derived from our AGCM simulation show like the observations also a general intensification of the equatorial circulation (Fig. 4b). Anomalously strong easterlies are simulated over the equatorial Pacific and anomalously strong westerlies over the Indian Ocean, with anomalously strong convergence in the far western Pacific, which is accompanied by anomalous low pressure in this region (Fig. 4c). The intensification of the easterlies over the tropical Pacific in the observations was also reported by Posmentier et al. (1989). However, it is still a matter of debate to which extent the trends in the wind observations are due to changing measurement techniques (e.g., Cardone et al. 1990). Our model results indicate that the trends might be real. However, there are large regional differences between the observed and simulated trend patterns. At this stage, we do not know whether these differences must be attributed to imperfections in the observations and/or the model simulation.

Largest explained variances are found in both the observations and the model simulation over the equatorial Pacific and amount to about $10 \%$ relative to the raw monthly anomalies in the centers of action (not shown). The intensification of the Pacific trade wind field near the equator should result in a cooling of the SSTs in the eastern and central equatorial Pacific. Stronger easterlies would induce enhanced Ekman divergence, which in turn would lead to enhanced equatorial upwelling and cooler SSTs. However, as shown above, the SSTs show a warming trend (Fig. 3a), although a relative minimum is found in the eastern and central equatorial Pacific. We therefore conclude that the observed warming trend must be forced by other processes than changes in the surface wind stress. Nevertheless, the changes in the wind stress might provide important dynamical feedbacks that can slow down the warming in the eastern equatorial Pacific, where the thermocline shoals, and enhance the warming in the west, where the thermocline deepens, in response to stronger easterlies.

The trends in the simulated sea level pressure (SLP) show reduced pressure over the Pacific and Indian Oceans and enhanced pressure over most of the Atlantic Ocean (Fig. 4c). Most significant are the reduction in SLP over the western equatorial Pacific and the increase in SLP over the western equatorial Atlantic, with explained variances of about $10 \%$ and $20 \%$ relative to the 
a) ENSO POP mode, real part

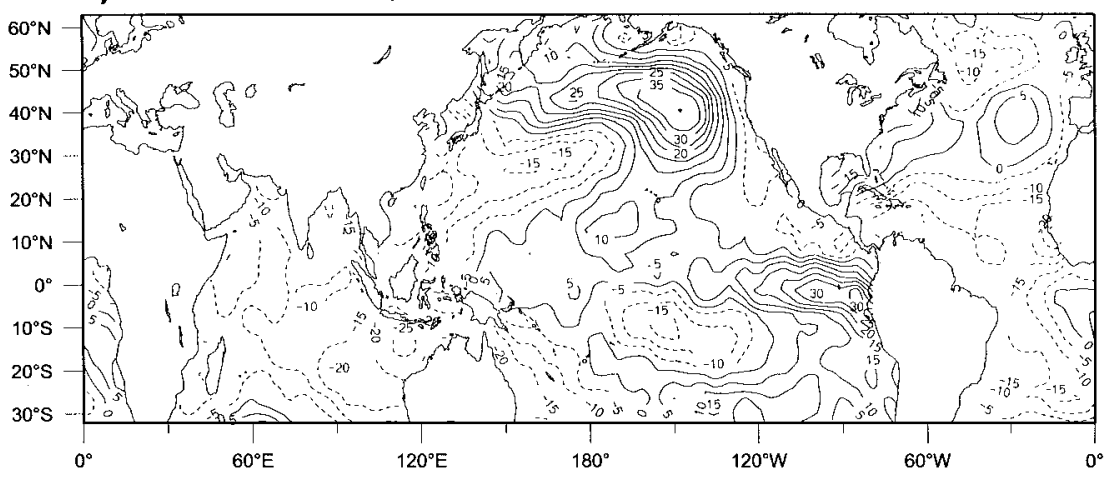

b) ENSO POP mode, negative imaginary part

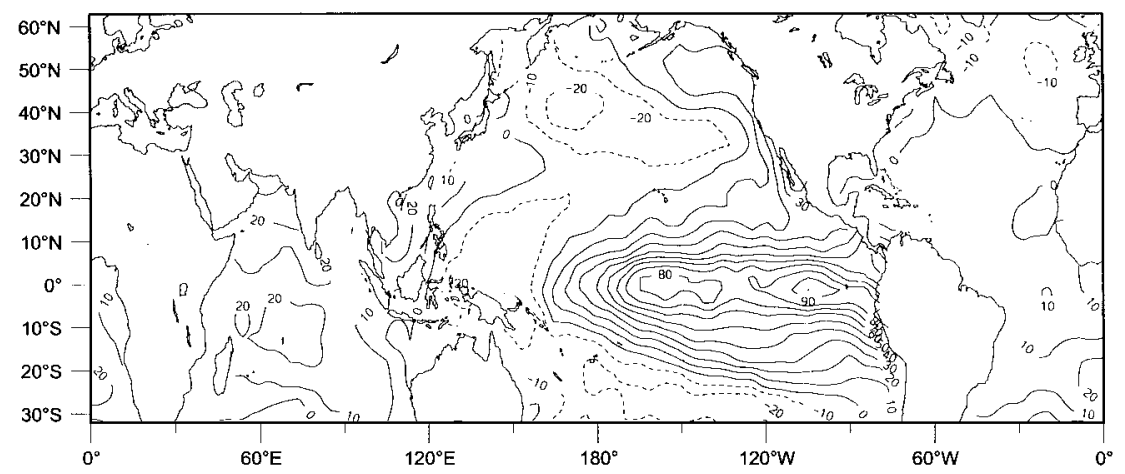

c) ENSO POP mode, explained variance

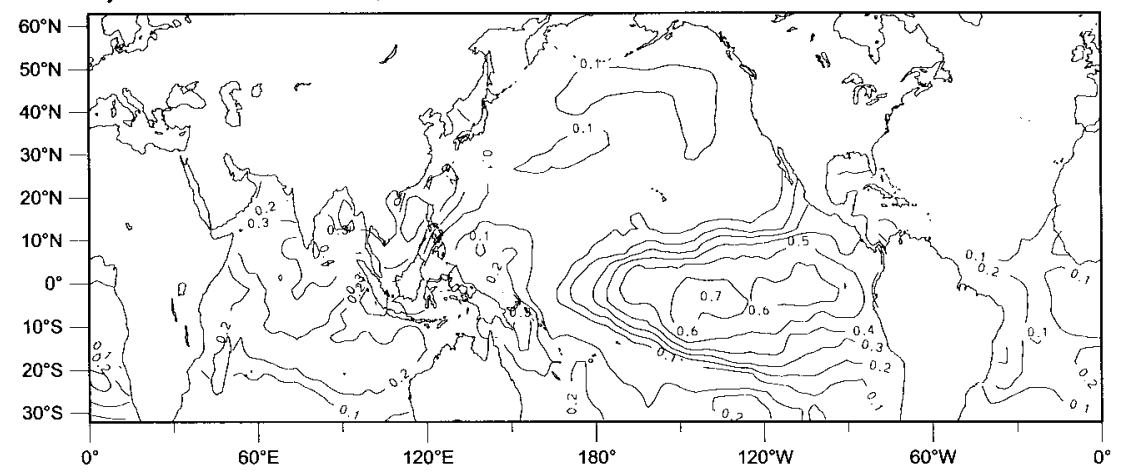

FIG. 6. POP patterns of the ENSO mode $\left({ }^{\circ} \mathrm{C}\right)$ : (a) real part, (b) (negative) imaginary part, and (c) variances explained by the ENSO mode.

raw monthly anomalies, respectively (not shown). Neither the tropical SLP nor the surface wind stress responses do show Southern Oscillation-type patterns (cf. Figs. 7 and 8). Thus, although the warming trend in the tropical Pacific is somewhat reminiscent of the conditions observed during El Niño (Fig. 6b), the associated changes in the atmosphere do not support the picture that the trend pattern looks like a "giant" El Niño. If the observed SST trends reflect greenhouse warming, our results contradict the model results of Meehl and Washington (1996), who argue that greenhouse warming in the tropical Pacific will look like present-day El Niños.
The trends in and over the entire Pacific are more consistent with a strengthened atmospheric circulation in response to enhanced tropical convection, and this is confirmed by the trends in the simulated precipitation, which show enhanced rainfall over the western equatorial Pacific (Fig. 4d). The regional variations in the SST trends observed are entirely consistent with this picture. The minimum in the warming of the eastern and central equatorial Pacific, the relatively strong warming of the warm pool in the western equatorial Pacific, the cooling of the North Pacific, all of those, might result from the changes in the atmospheric circulation associated with enhanced tropical convection. 
a) wind stress anomalies [mPa] associated to real part of ENSO POP mode, COADS

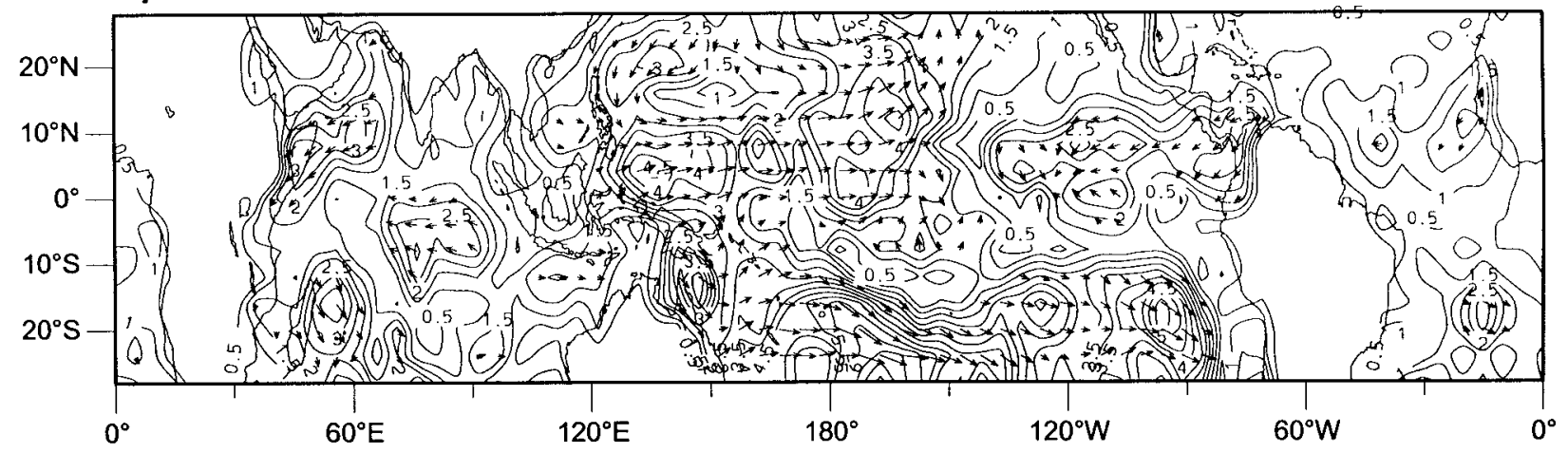

b) wind stress anomalies [mPa] associated to real part of ENSO POP mode, ECHAM3
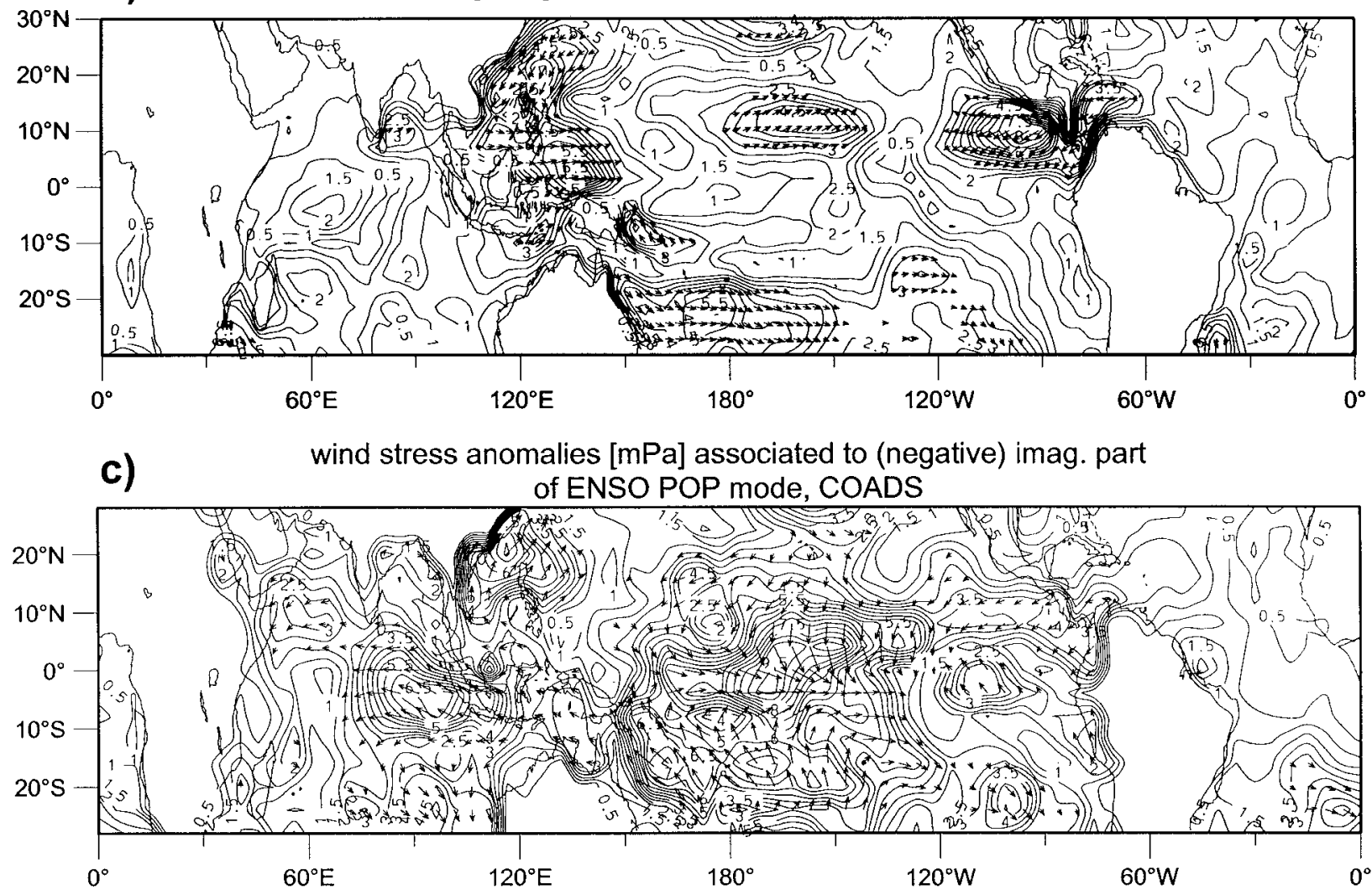

wind stress anomalies [mPa] associated to (negative) imag. part

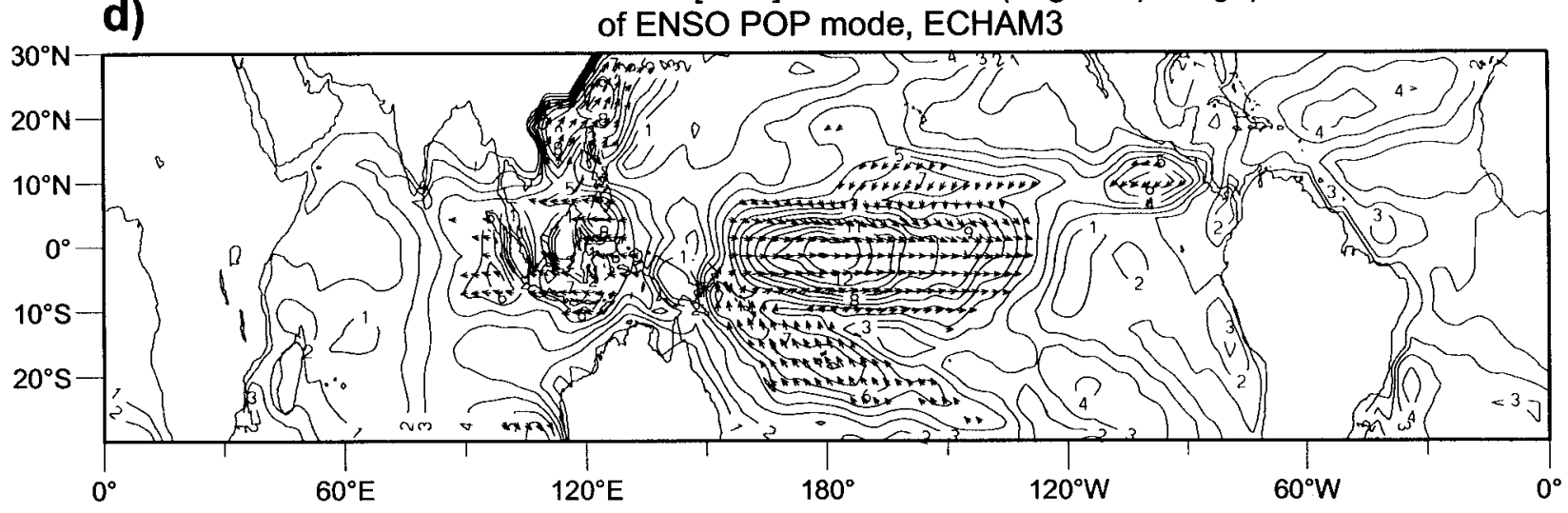


Thus, greenhouse warming might evolve conceptually in two steps. In the first step, tropical convection is enhanced by the nonlinear water vapor feedback. Then, in the second step, the dynamical feebacks associated with the enhanced atmospheric circulation will lead to the characteristic spatial SST variations observed. To test this hypothesis, additional numerical experimentation, however, is required and under way.

\section{b. ENSO mode}

We now turn to the POP analysis of the UKMO SSTs. The linear trend in SST discussed above was removed from the SST data, and they were slightly smoothed by applying a 5-month running mean filter prior to the POP analysis. The results of the POP analysis, however, remain basically unchanged when the trend is left in. In this case the trend is represented by a real POP mode. We would like to emphasize that our results do not depend on the analysis technique used. Canonical Correlation Analyses (CCAs) were also performed using the observed SST anomalies and the observed or simulated wind stress anomalies, and the CCAs are entirely consistent with the POP results. In particular, the CCAs yielded decadal modes with spatial structures markedly different to that of ENSO, a feature that is discussed below on the basis of the POP results. We do not show the CCA results here for the sake of brevity.

Here, we discuss the two most energetic POP modes of the SST variability. The most energetic mode is associated with the ENSO phenomenon and accounts for about $25 \%$ of the total SST variance. The second most energetic POP mode accounting for about $10 \%$ of the variance exhibits considerable decadal variability and will be referred to as the decadal mode (section 3c). The decadal POP mode shows some aspects of the North Pacific mode described in detail by Latif and Barnett (1994), Latif and Barnett (1996), and Robertson (1996). The observational SST record used here, however, is much too short to address the question as to whether the decadal POP and the North Pacific modes describe the same phenomenon.

The ENSO POP mode has a rotation period of about 40 months and a damping time of about 44 months. For convenience, we display here the positive real and negative imaginary part of the ENSO POP mode because they follow each other in time according to (1), so that the evolution of the SST anomalies associated with this POP mode is easy to follow. The ENSO POP mode shows the well-known features described in many papers (e.g., Rasmusson and Carpenter 1982; Weare et al. 1976; Kawamura 1994). Although the ENSO POP mode does not provide any new results, we display it here for the sake of comparison with the other variability modes. The two POP coefficient time series (Fig. 5) show clearly the observed extremes in the ENSO cycle. An inspection of the spectra of the POP coefficient time series revealed two peaks, one near 60 and one near 30 months (not shown), which is consistent with many other observational studies (e.g., Rasmusson and Carpenter 1982; Barnett 1991). The ENSO mode also exhibits some decadal variability as witnessed by the POP coefficient time series. There exists, however, a decadal mode that is independent of ENSO, as described below.

The SST anomalies associated with the ENSO mode evolve basically as a standing oscillation, with weak SST anomalies occuring first in the eastern equatorial Pacific and then spreading westward (Figs. 6a and 6b). The largest explained variances are found in the eastern and central equatorial Pacific and in the equatorial Indian Ocean (Fig. 6c). The SST anomalies during the ENSO extremes (Fig. 6b) are strongest in the eastern equatorial Pacific, with weaker anomalies of the same sign in the equatorial Indian Ocean and of opposite sign in the North Pacific. We would like to emphasize that the 5-yr mean SST anomalies (Fig. 1) are not associated with strong SST anomalies in the eastern equatorial Pacific, which is the ENSO key region. Thus, in order to describe the anomalous 1990 s it is not adequate to refer to an "extended" or "permanent" El Niño.

The atmospheric changes associated with the ENSO POP mode as derived from the observed stresses and the AGCM simulation are shown in Figs. 7 and 8. Overall the model reproduces reasonably well the evolution in surface stress (Fig. 7). Both the observations and the model show the well-known features: The SST anomalies in the eastern and central equatorial Pacific are accompanied by westerly wind stress anomalies over the western and central equatorial Pacific (Figs. 7c and 7d) and the characteristic Southern Oscillation pattern in SLP (Fig. 8b). These features are highly significant as was derived from the corresponding maps of explained variances (not shown). The atmospheric fields derived from the ENSO mode are distinctly different from those associated with the SST trend (Fig. 4). While the trends indicate a strengthening of the trade winds over the Pacific, ENSO is associated with a weakened equatorial circulation. This supports the view that other dynamical processes than those involved in ENSO must cause the warming trend.

\section{c. Decadal mode}

The second most energetic POP mode explaining about $10 \%$ of the SST variance will be referred to as

FIG. 7. Associated patterns of observed and simulated wind stress anomalies (mPa) with respect to the ENSO POP mode: (a) real part derived from the observations, (b) real part derived from the simulation, (c) (negative) imaginary part derived from the observations, (d) (negative) imaginary part derived from the simulation. 
a) SLP anomalies $[\mathrm{hPa}]$ associated to real part of ENSO POP mode, ECHAM3

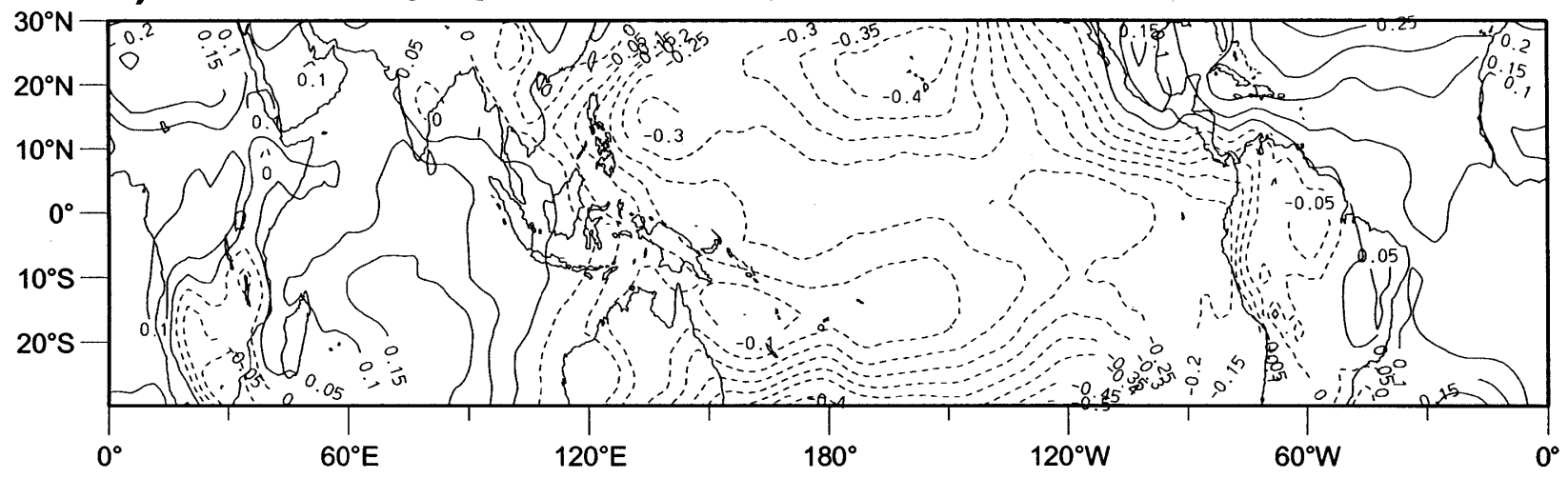

b) SLP anomalies [hPa] associated to (negative) imag. part of ENSO POP mode, ECHAM3

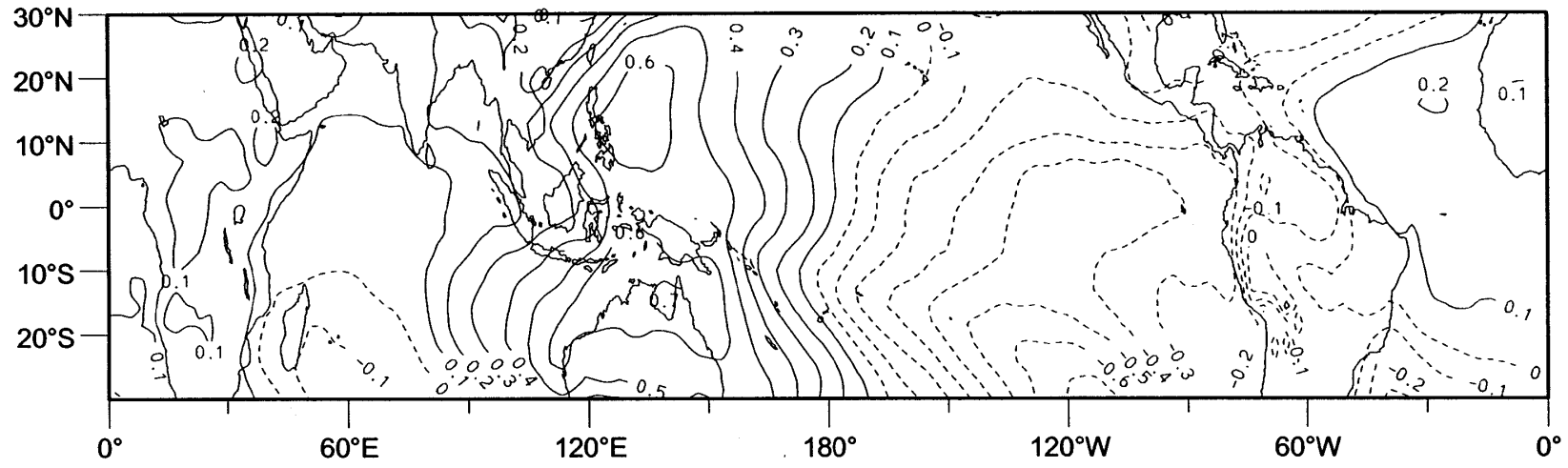

FIG. 8. Associated patterns of simulated sea level pressure anomalies (hPa) with respect to the ENSO POP mode: (a) real part, (b) (negative) imaginary part.

the decadal mode. It has a rotation period of about 13 $\mathrm{yr}$ and a damping time of about 4 yr. We would like to point out that timescale estimates from such relatively short records are subject to large uncertainties. More

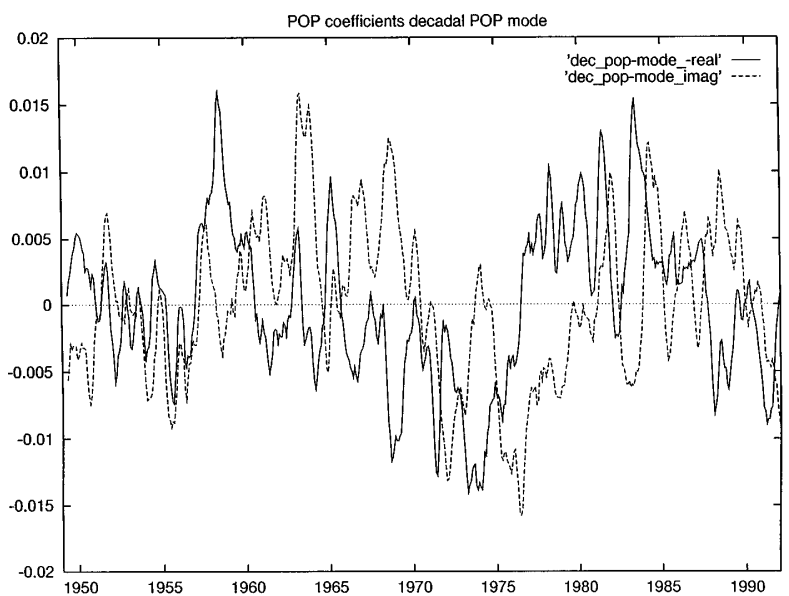

FIG. 9. POP coefficient time series of the decadal POP mode. The (negative) real part is given by the full line, while the imaginary part is given by the dashed line. important to our discussion, however, are the spatial structures, and we base our discussion of the anomalous 1990s mostly on the different spatial patterns. To facilitate the description of the decadal POP mode, we rotated it in such a way that the correlation of northeastern Australian rainfall anomalies is maximized with respect to the imaginary part. The rotation in the complex POP plane can be done without loss of generality.

As expected from the rotation period, the POP coefficient time series of the decadal POP mode show considerable decadal variability, with some interannual variability superimposed (Fig. 9). The POP pattern of the imaginary part (Fig. 10b) exhibits positive SST anomalies in all three tropical oceans, with a horseshoetype pattern in the tropical Pacific and positive SST anomalies along the west coast of North America. The horseshoe pattern in tropical Pacific SST associated with the decadal POP mode shows some similarities to the anomalous conditions observed during the 1990s (Fig. 1). The rotation from the (negative) real part to the imaginary part indicates that the SST anomalies associated with the horseshoe originate in the subtropics at the west coasts of North and South America (Fig. 10a). This is supported by the explained variances (Fig. 10c), 
a) decadal POP mode, (negative) real part

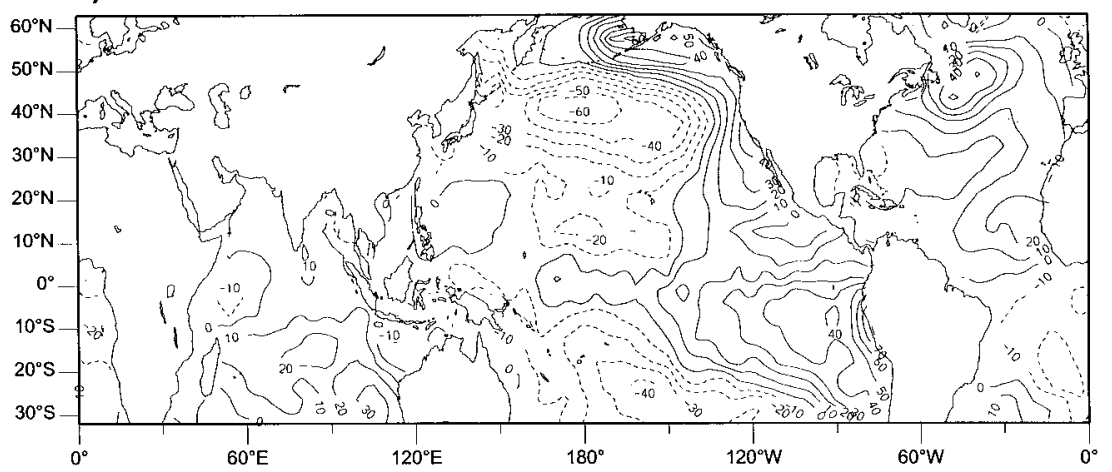

b) decadal POP mode, imaginary part

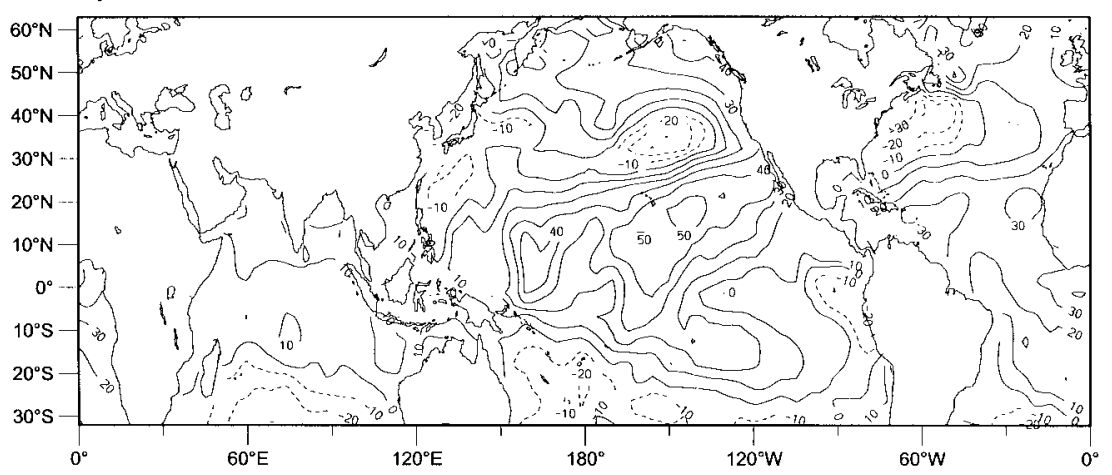

C) decadal POP mode, explained variances

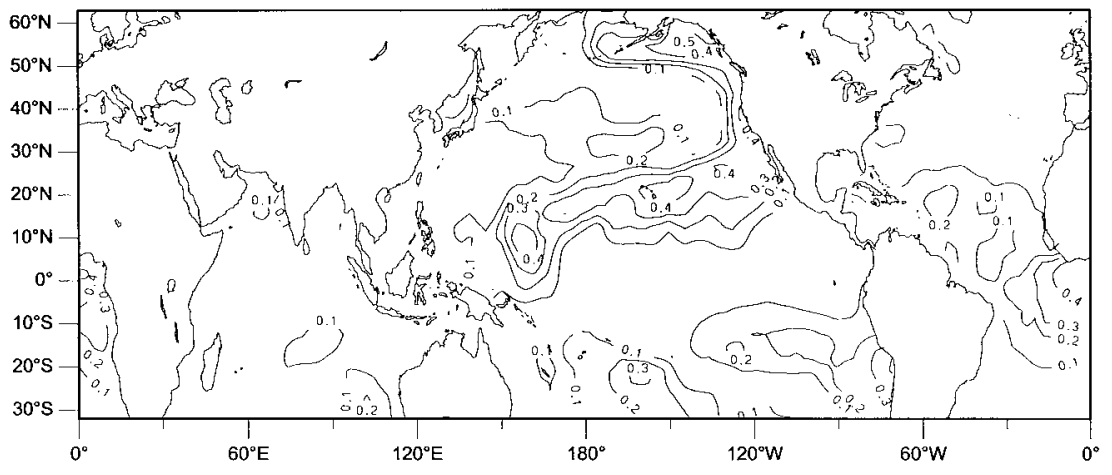

FIG. 10. POP patterns of the decadal mode $\left({ }^{\circ} \mathrm{C}\right)$ : (a) (negative) real part, (b) imaginary part, and (c) variances explained by the decadal mode.

which show relatively high values in these two regions. Explained variances are also relatively high along the northern lobe of the horseshoe and in the tropical Atlantic, especially in the Southern Hemisphere. The decadal mode does not account for much variance in the Indian Ocean and in midlatitudes. We note two more points: First, the evolution of the SST anomalies in the tropical Pacific according to the decadal POP mode is somewhat reminiscent of that expected from subduction processes (e.g., Liu et al. 1994; McCreary and Pu 1994). Analysis of subsurface observations and further numerical experimentation, however, are needed to address this topic in detail. Second, one phase of the decadal
POP mode (the unrotated imaginary part) looks very much like the trend mode. So, the continuation of the trend might favor the conditions for the decadal mode.

The decadal mode is not connected with strong SST anomalies in the eastern equatorial Pacific and it does not account for much variance in this region either. We therefore conclude that the decadal mode is distinct from the ENSO phenomenon. The impact of the decadal mode on the tropical climate system, however, is somewhat similar to that observed during ENSO extremes. The horseshoe pattern in SST is associated with westerly wind stress anomalies in the western and central equatorial Pacific, that are centered near $10^{\circ} \mathrm{N}$ and easterly 
a) wind stress anomalies $[\mathrm{hPa}]$ associated to (negative) real part

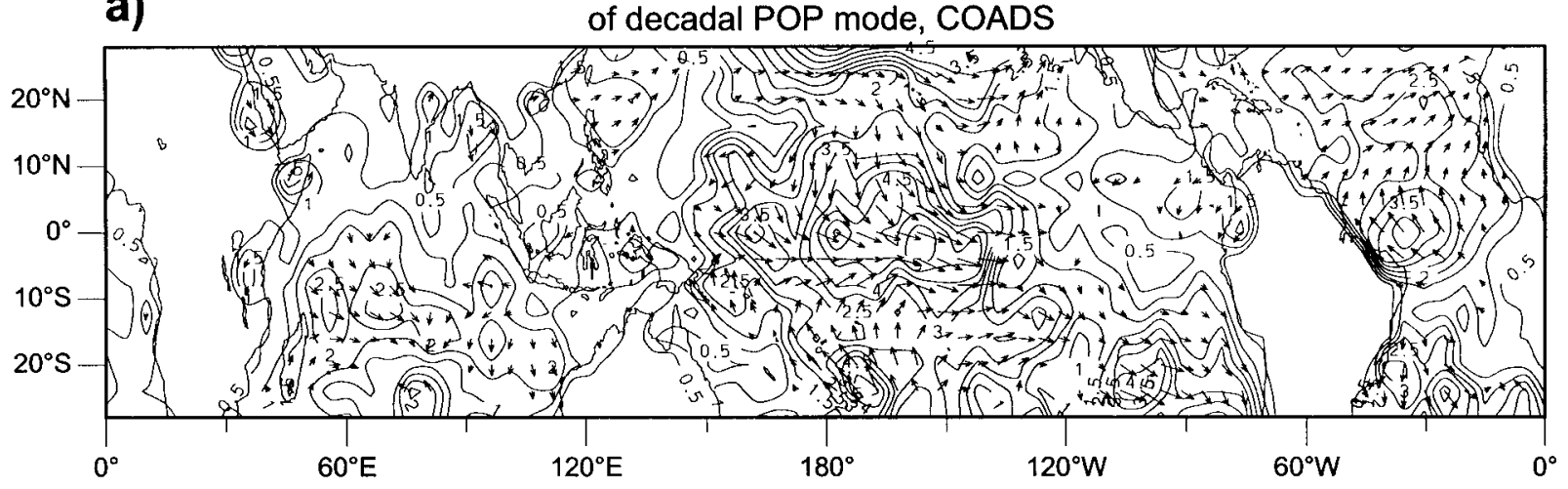

b) wind stress anomalies [mPa] associated to (negative) real part

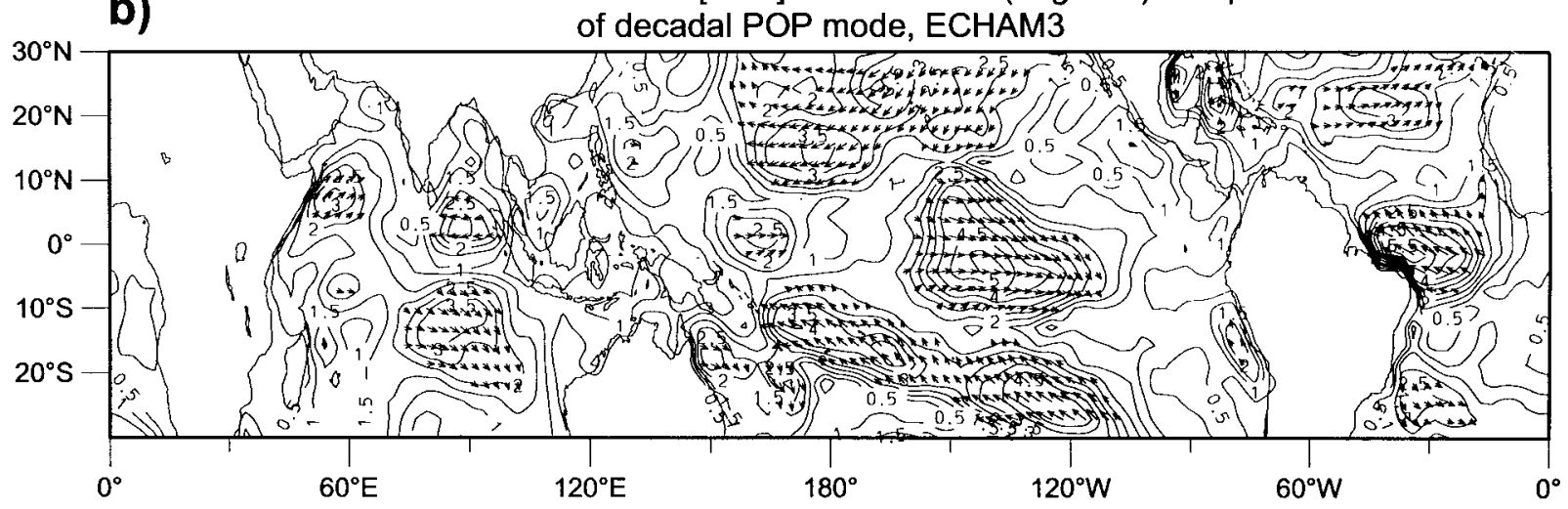

c) wind stress anomalies [mPa] associated to imag. part of decadal POP mode, COADS

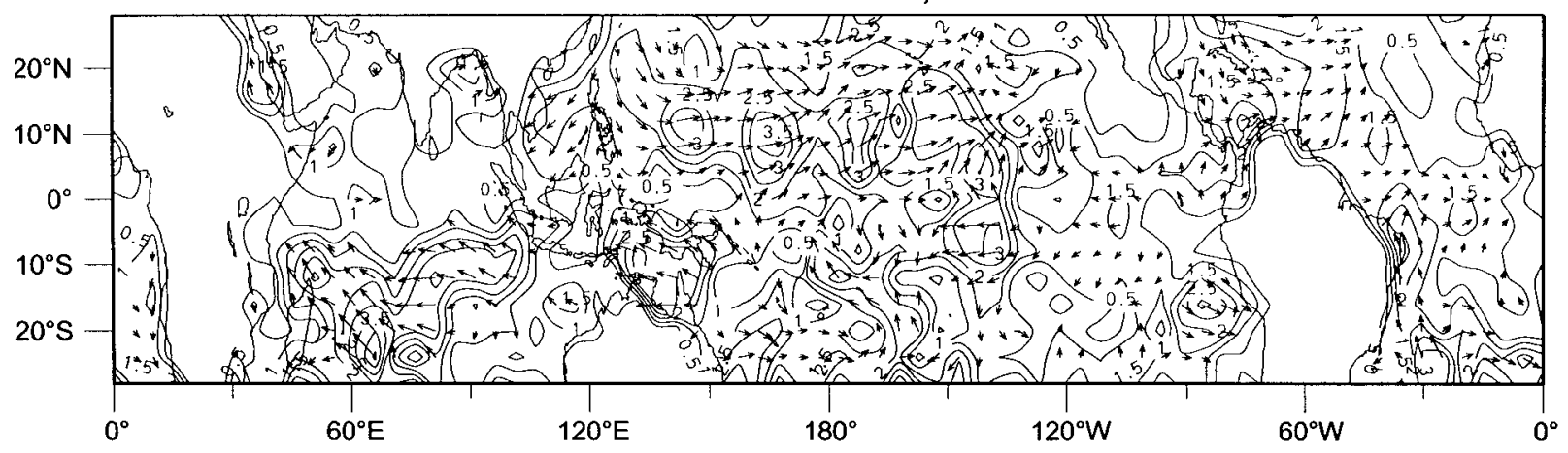

wind stress anomalies $[\mathrm{mPa}]$ associated to imag. part of decadal POP mode, ECHAM3

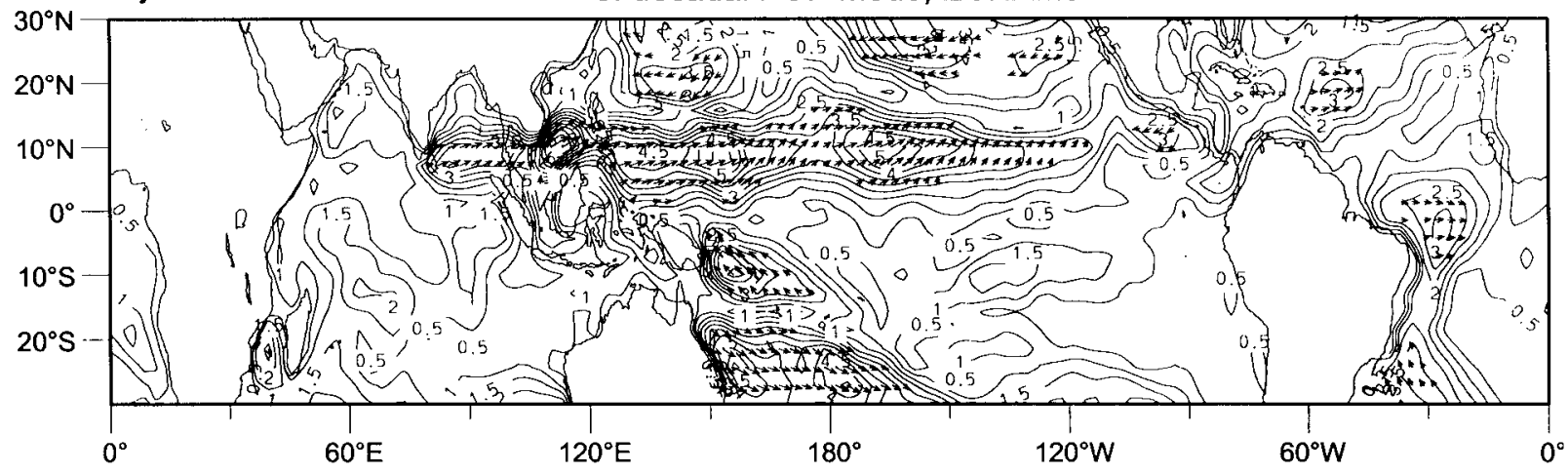


wind stress anomalies over the equatorial Indian Ocean (Fig. 11), and there is an indication of a Southern Oscillation-type response (Fig. 12), with anomalously high SLP centered over Indonesia and anomalously low SLP over the eastern Pacific. The explained variances in the atmospheric fields are generally low (not shown). However, the changes associated with the decadal POP mode account for a considerable fraction of the decadal variability in the atmospheric fields. The explained variances amount to about $30 \%$ in the centers of action when the data were smoothed with a 5-yr running mean filter (not shown).

The existence of the decadal mode is also supported by an investigation of the observed northeastern Australian summer (DJF) monsoon rainfall, an independent dataset. Decadal fluctuations in this quantity are highly (anti-)correlated with the imaginary part of the decadal POP mode (Fig. 13). The correlation between the two time series amounts to about -0.8 , which is significant at the $99 \%$ level. Further, the cross-correlation functions between the (negative) real and the imaginary parts of the decadal POP mode with the anomalous northeastern Australian summer monsoon rainfall are characteristic of a periodic process with a decadal timescale (Fig. 14).

Thus, the analyses of the observations reveal that decadal fluctuations in northeastern Australian rainfall are strongly linked to decadal variations in tropical SST. The decadal SST changes, however, cannot be attributed simply to decadal changes of the ENSO mode, which was revealed from a correlation analysis of the low-pass filtered ENSO POP coefficients with the northeastern Australian rainfall (not shown). The correlations of the low-pass-filtered coefficients of the ENSO POP mode with the northeastern Australian summer monsoon rainfall do not exceed values of 0.5 at any lag. The pattern of the decadal SST variability that accompanies decadal fluctuations in northeastern Australian rainfall is distinctively different from the pattern of the SST variability associated with ENSO. While the latter is connected primarily with strong SST anomalies in the eastern equatorial Pacific, the decadal mode exhibits strongest SST anomalies in the western equatorial Pacific and off the equator, and it is this characteristic horseshoe pattern that goes along with the decadal rainfall fluctuations over northeastern Australia.

\section{The anomalous $1990 \mathrm{~s}$}

To understand the anomalous 1990s in more detail, we projected the SST data onto the variability modes described above. By doing so we obtain pseudo principal components (PPCs), and the amplitudes of the
PPCs provide an objective measure of the strengths of the modes during the analyzed period. To highlight the SST variations in the tropical Pacific, we restricted the projection to the tropical Pacific Ocean only. The projections onto the trend pattern do not show an upward tendency during the 1990s (Fig. 15). If anything, there is even a slight cooling tendency in the PPCs. Thus, we conclude that the anomalous 1990s cannot be explained by the background trend in SST.

We then projected the SST data onto the ENSO POP mode (Fig. 16). The PPCs of the (negative) imaginary part (which is a good index of ENSO extremes) derived from both the UKMO and NMC SSTs show clearly that the year 1991 was a warm ENSO year in our definition. After 1991, however, no evidence for a strong ENSO activity is found. The period 1992-94 is characterized instead by weak high-frequency ENSO-like variations. The projection of the NMC data onto the decadal POP mode supports the visual impression that the anomalous 1990s were indeed dominated by the decadal mode (Fig. 17). The amplitude of the ENSO POP mode is generally stronger than that of the decadal POP mode prior to 1990. However, the amplitude of the decadal POP mode is well developed after 1990, while it is relatively weak for the ENSO mode (Fig. 18). The 1990s are the only time when the amplitude of the decadal POP mode is even stronger that that of the ENSO POP mode. We conclude therefore that the anomalous 1990s are mainly caused by the decadal mode, with some weak and shortperiod ENSO fluctuations superimposed.

\section{Hybrid coupled model results}

To study the sensitivity of ENSO to the low-frequency wind stress changes associated with the trend and decadal mode, we conducted a series of 100-yr integrations with our hybrid coupled model. The HCM simulates quasi-regular oscillations with a period of $5 \mathrm{yr}$, when run under unperturbed conditions (Fig. 20, later in this section). The oceanic background conditions are changed by adding to the climatological wind stress field idealized low-frequency surface wind stress anomalies obtained from the simulation with the ECHAM-3 model.

The HCM was forced first by the low-frequency wind stress changes that are associated with the linear trend. For this purpose, a wind stress anomaly was added to the HCM, which has the spatial structure shown in Fig. $4 \mathrm{~b}$ and evolves linearly in time according to the trend coefficients. The trend-related stress anomalies are zero during the middle of the experiment. The HCM is sensitive to the trend in the wind stress. As expected, eastern equatorial Pacific SST anomalies in the Niño-3 re-

FIG. 11. Associated patterns of observed and simulated wind stress anomalies (mPa) with respect to the decadal POP mode: (a) (negative) real part derived from the observations, (b) (negative) real part derived from the simulation, (c) imaginary part derived from the observations, and (d) imaginary part derived from the simulation. 


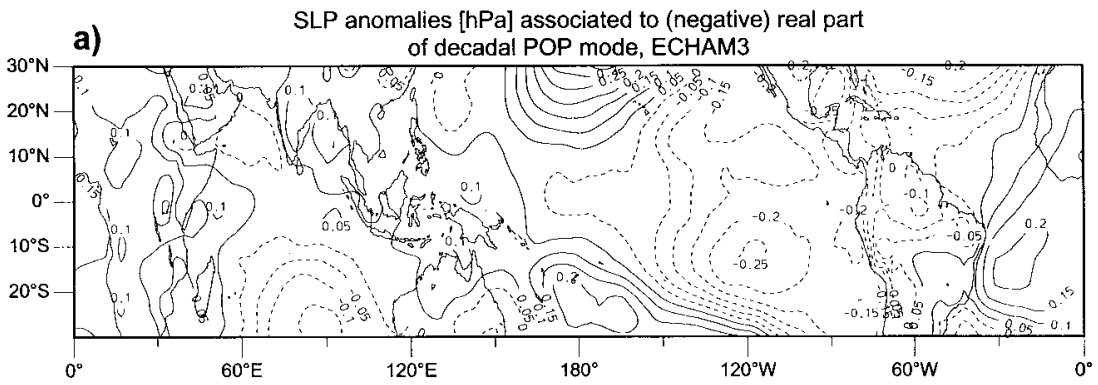

b) SLP anomalies [hPa] associated to imag. part of decadal POP mode, ECHAM3

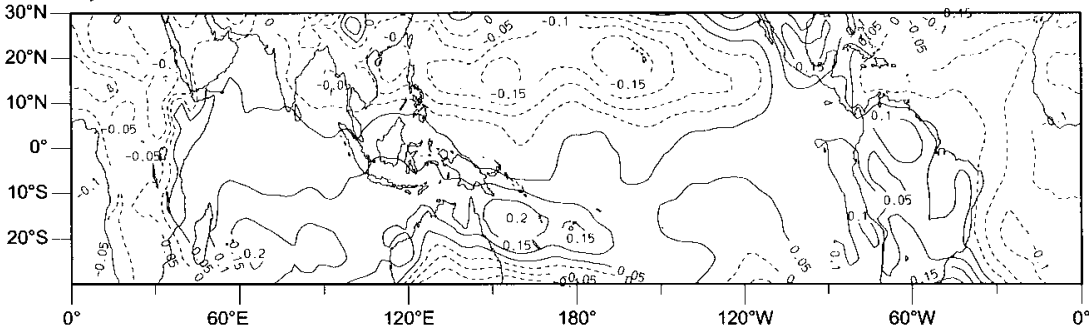

FIG. 12. Associated patterns of simulated sea level pressure anomalies (hPa) with respect to the decadal POP mode: (a) (negative) real part, (b) imaginary part.

gion show a gradual cooling, which can be attributed to enhanced equatorial upwelling in response to the strengthening of the trade winds in the equatorial region. The HCM simulates quasi-regular oscillations during the middle of the experiment, when the wind stress anomalies associated with the trend are small (Fig. 19). No interannual oscillations, however, are simulated when the "trend anomalies" are well developed. The HCM undergoes two bifurcations: Near year 30, the system switches from a quasi-stationary regime with weak interannual variability to an oscillatory regime,

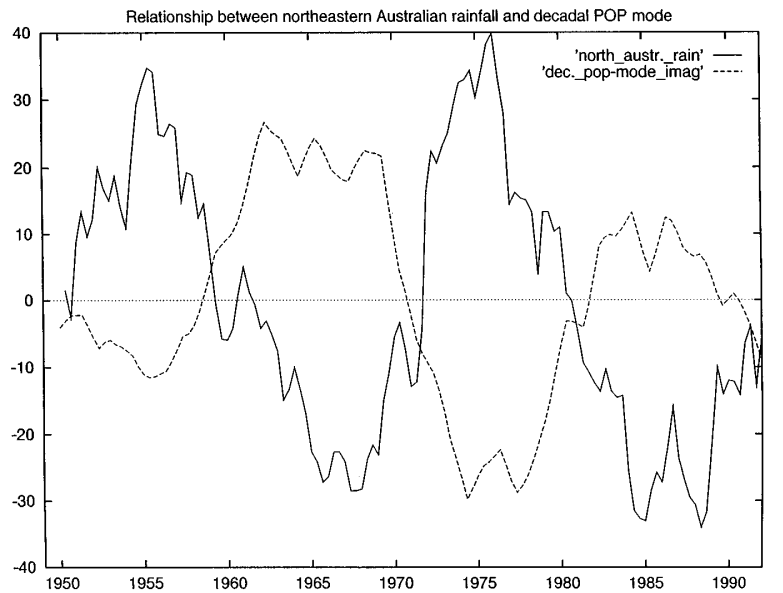

FIG. 13. Relationship between the decadal POP mode and northeastern Australian rainfall anomalies $(\mathrm{mm})$. Shown are the low-passfiltered (retaining variability with periods longer than $5 \mathrm{yr}$ ) anomalous summer (DJF) rainfall (solid) and the corresponding values of the imaginary part of the decadal POP mode (processed in the same way) shown in Fig. 9. The POP coefficient time series was scaled to match the amplitude of the rainfall index. while near year 70 the interannual oscillations are replaced by a small residual annual cycle. Very similar behavior is simulated by the HCM when the experiment is started from different initial conditions.

We then investigated the sensitivity of the HCM to the wind stress changes associated with the decacal POP mode (Figs. 11b and 11d). To keep the experiments as simple as possible, the two surface wind stress patterns associated with the decadal POP mode were assigned a sinusoidal time evolution. Furthermore, we assumed a rotation period of $20 \mathrm{yr}$ and an infinite damping time.

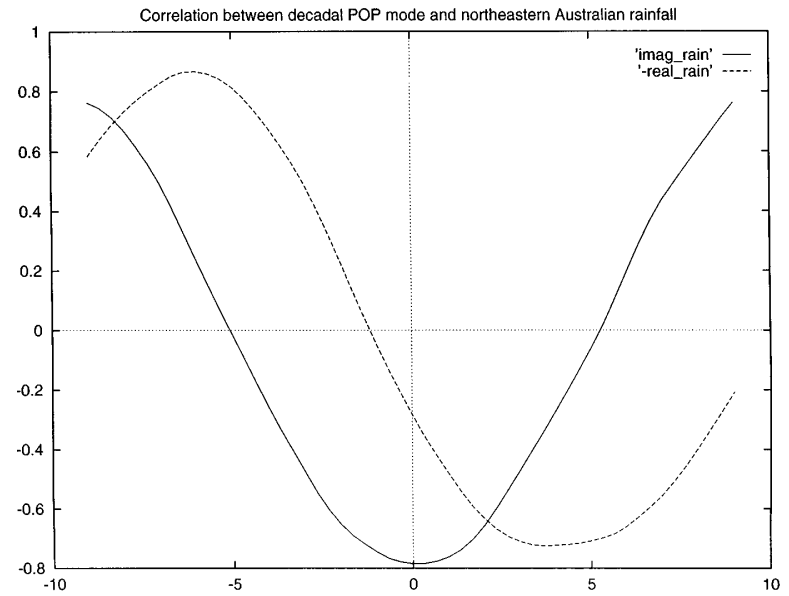

FIG. 14. Lagged cross correlations between the low-pass-filtered (retaining variability with periods longer than $5 \mathrm{yr}$ ) anomalous summer (DJF) rainfall (shown in Fig. 13) and the corresponding POP coefficient time series of the decadal POP mode (processed in the same way). The correlation of the rainfall index with the imaginary part is given by the solid line and that with the (negative) real part by the dashed line. 


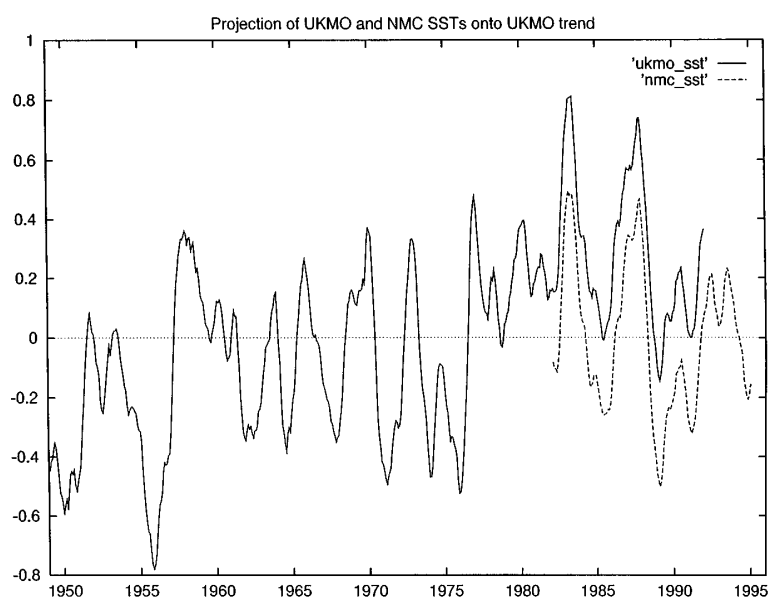

FIG. 15. Projection of the UKMO (full line) and NMC SSTs (dashed line) onto the trend pattern shown in Fig. 2. Please note that the offset between the two datasets are caused by the different record lengths.
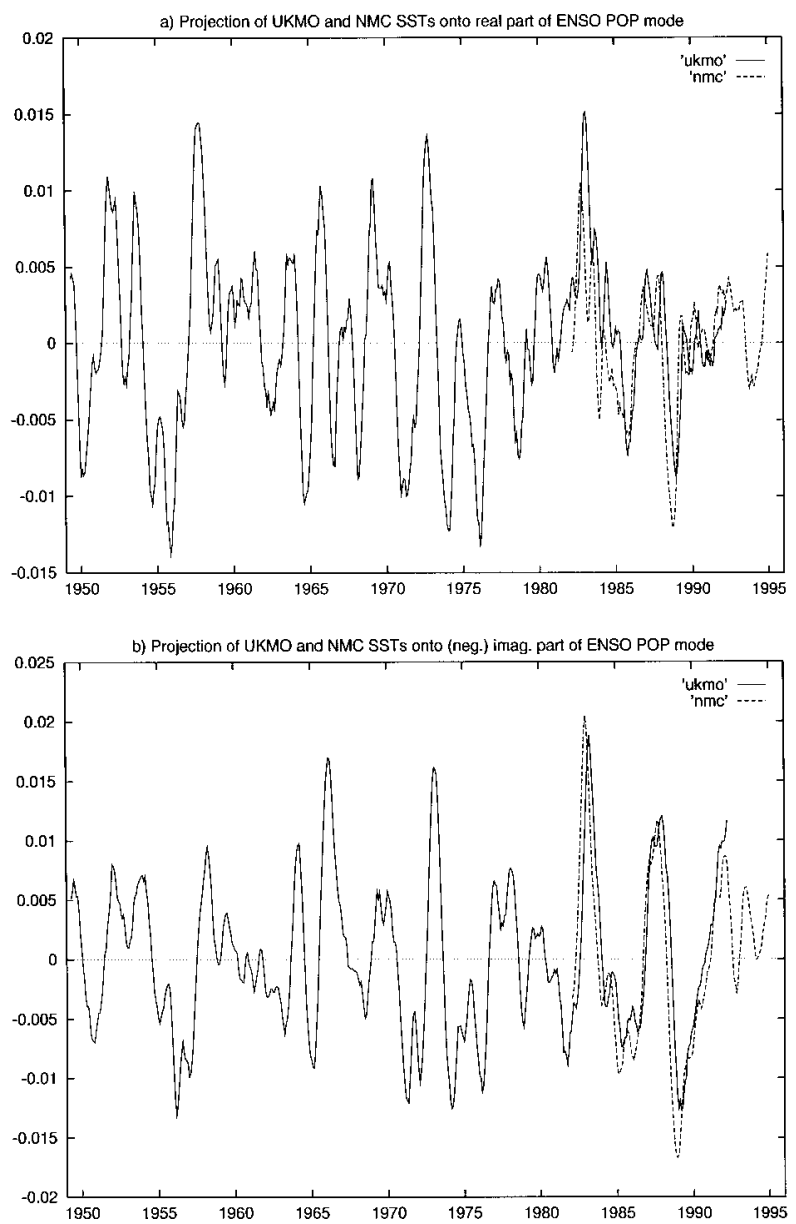

FIG. 16. Projection of the UKMO (full line) and NMC SSTs (dashed line) onto the ENSO POP mode shown in Fig. 6: (a) projection onto the real part, (b) projection onto the (negative) imaginary part.
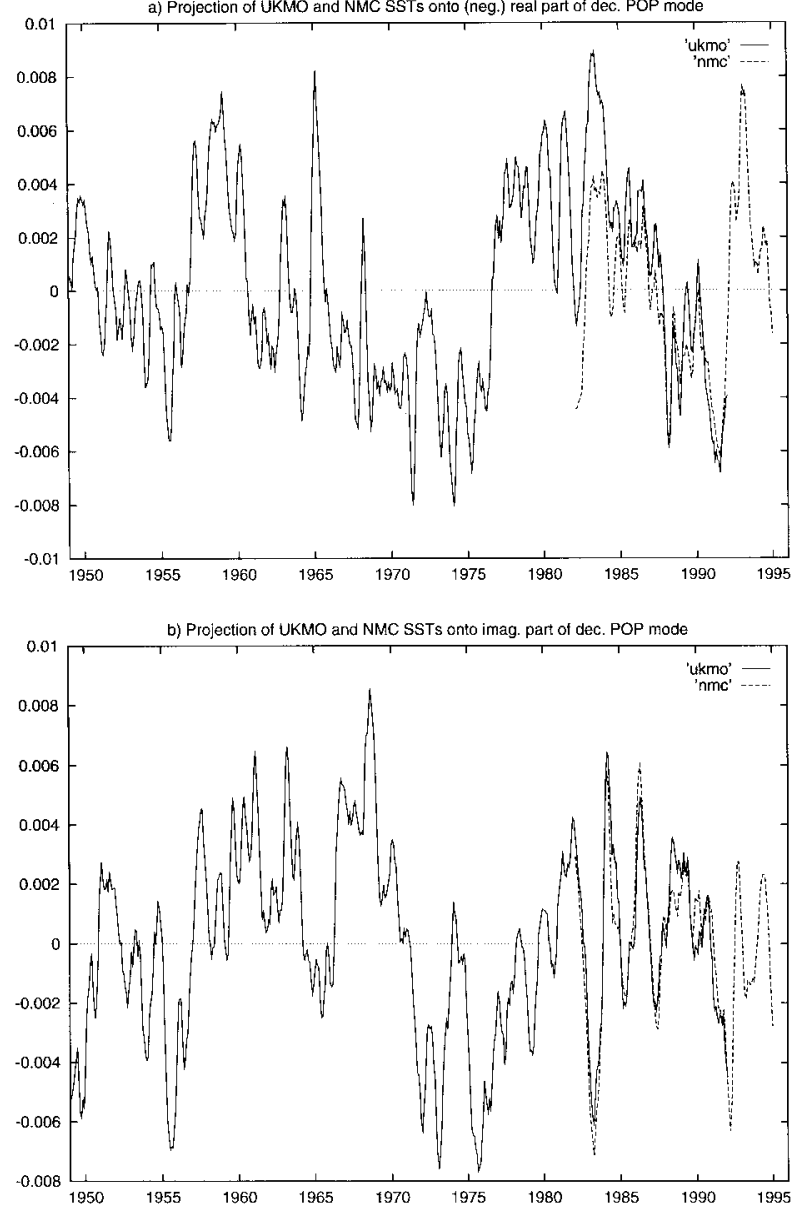

FIG. 17. Projection of the UKMO (full line) and NMC SSTs (dashed line) onto the decadal POP mode shown in Fig. 10: (a) projection onto the (negative) real part, (b) projection onto the imaginary part.

Thus, we allow the POP cycle to repeat itself undamped. To investigate the sensitivity of the ENSO cycle to the strength of the decadal wind stress fluctuations, three experiments were performed, corresponding to a twostandard deviation, two-and-a-half-standard deviation, and three-standard deviation change in the decadal POP mode, respectively. The three experiments show clearly that the HCM is sensitive to the wind stress changes induced by the decadal POP mode. As the amplitude of the forcing is increased, the interannual variability becomes increasingly irregular and the level of interannual variability decreases. In conclusion, the changes in the oceanic background conditions induced by realistic lowfrequency wind stress fluctuations can have an important impact on the ENSO cycle.

\section{Summary and discussion}

We have investigated the dominant variability modes in the Tropics by analyzing the SSTs observed during the period 1949-94, observed wind stresses and northeastern Australian rainfall, and the output of a multi- 

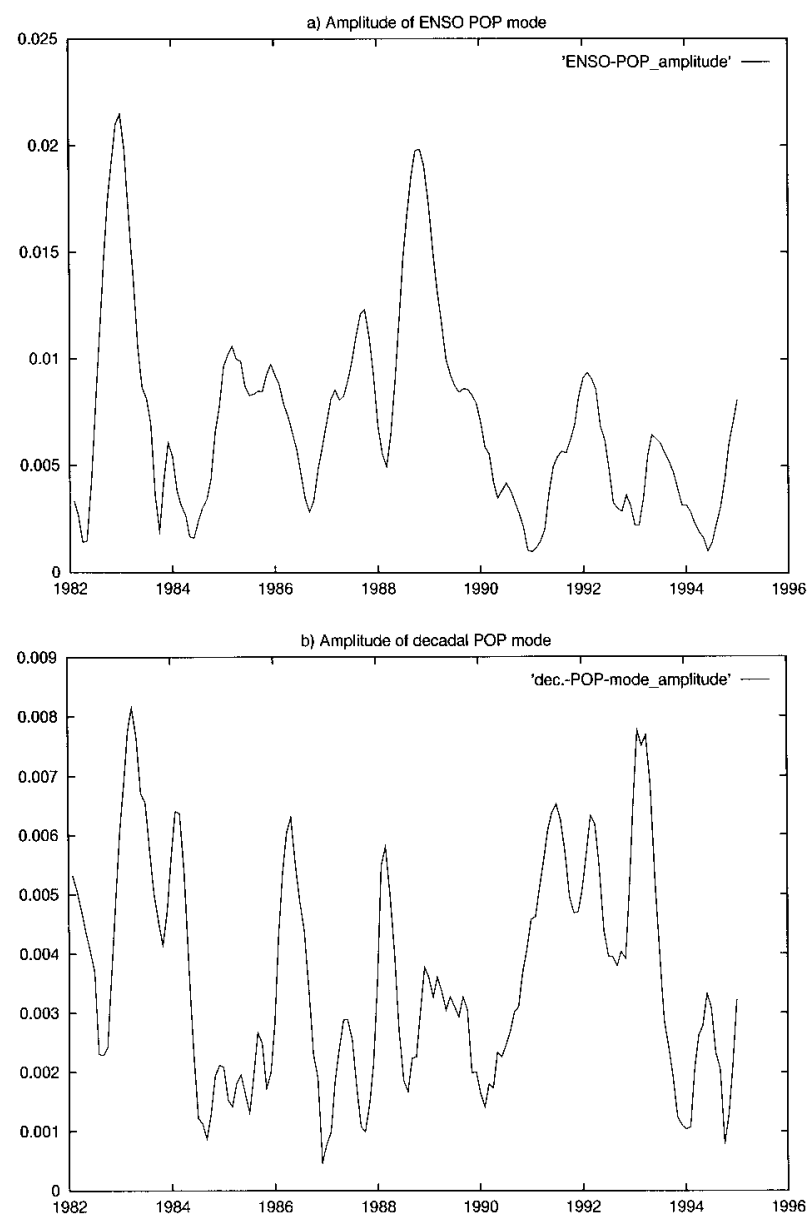

FIG. 18. Amplitudes of the (complex) pseudo principal components of the ENSO (a) and decadal POP modes (b), as derived from the NMC SSTs for the period 1982-94.

decadal run with an atmospheric general circulation model forced by observed SSTs. Three modes were identified: A trend or not resolved ultra-low-frequency variability, the ENSO, and a decadal mode. Our analysis indicates that the anomalous 1990s were dominated by the decadal mode, whereas the ENSO cycle and the trend were not well developed.

Although the shortness of the instrumental record used here precludes any definite statement about existence of the decadal mode in the tropical climate system, additional support for the existence of such an oscillation comes from long instrumental records of surface temperature (Ghil and Vautard 1991; Mann and Park 1994). Four different coral records varying in length from 170 to $370 \mathrm{yr}$ also have some evidence for spectral peaks in the decadal frequency band. These records are from widely scattered sites in the tropical Pacific basin, the New Hebrides (Quinn et al. 1993), the west coast of Central America (Linsley et al. 1994), the Galapagos Islands (Dunbar et al. (1994), and New Caledonia (T. J. Crowley 1996, personal communication). Although more statistical work would be required to establish

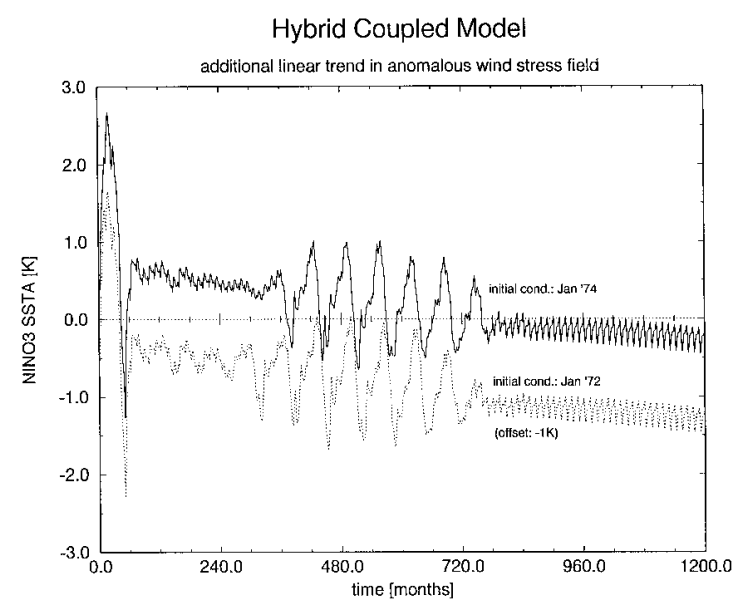

FIG. 19. Time series of eastern equatorial Pacific SST anomalies $\left({ }^{\circ} \mathrm{C}\right)$ in the Niño-3 region as simulated by the hybrid coupled model when forced by the anomalies associated with the trend in the wind stress shown in Fig. 4b. Two experiments were performed with different initial conditions. The time series showing the experiment initialized in January 1972 has an offset of $-1^{\circ} \mathrm{C}$.

higher confidence that the coral records are recording the same phenomena as we discuss, we consider the coincidence in timing highly suggestive.

The decadal mode has a horseshoe-type signature in the tropical Pacific, with strongest SST anomalies in the western equatorial Pacific, extending to the northeast and southeast. The tropical climate impact of the decadal mode resembles somewhat that observed during ENSO extremes, with westerly wind anomalies over the western and central equatorial Pacific and anomalous dry conditions over northeastern Australia. The decadal mode is distinct from the ENSO mode not only because of the different timescales, but also because the spatial structure of the two modes differ considerably. While the ENSO mode has strongest SST anomalies in the eastern equatorial Pacific, the decadal mode shows strongest SST anomalies in the western equatorial Pacific and off the equator. It is therefore important to distinguish the ENSO from the decadal mode from a dynamical point of view. Latif and Barnett (1994) and Latif and Barnett (1996) have offered one plausible physical explanation for the decadal mode. However, subduction processes might also contribute to the generation of decadal variability (e.g., Gu and Philander 1997). Since subsurface observations are rather sparse, long integrations with coupled ocean-atmosphere models are needed to investigate the dynamics of the decadal mode in more detail.

The impact of the decadal mode on the ENSO cycle is still unclear, and we were not able to identify a simple relationship between the decadal mode and ENSO neither in the observations nor in the hybrid coupled model runs. Even in the idealized experiments with our hybrid coupled model, the interactions between the two modes were rather complicated. We have shown that the de- 
a) HCM POP cycle forcing

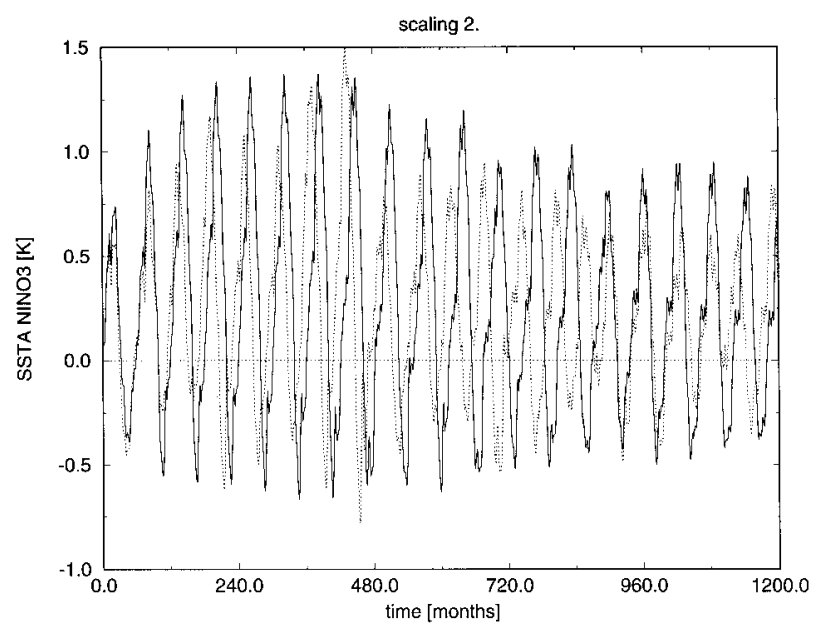

b) HCM POP cycle forcing

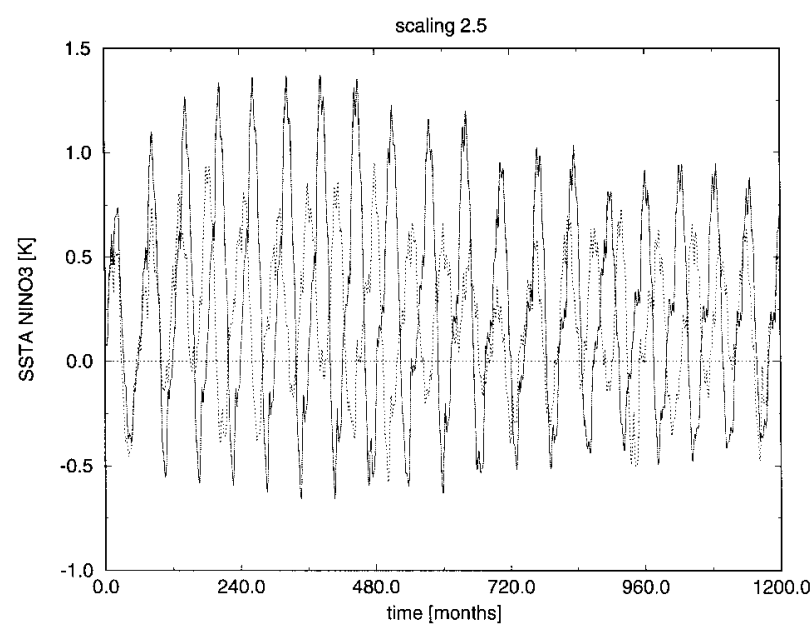

c) HCM POP cycle forcing

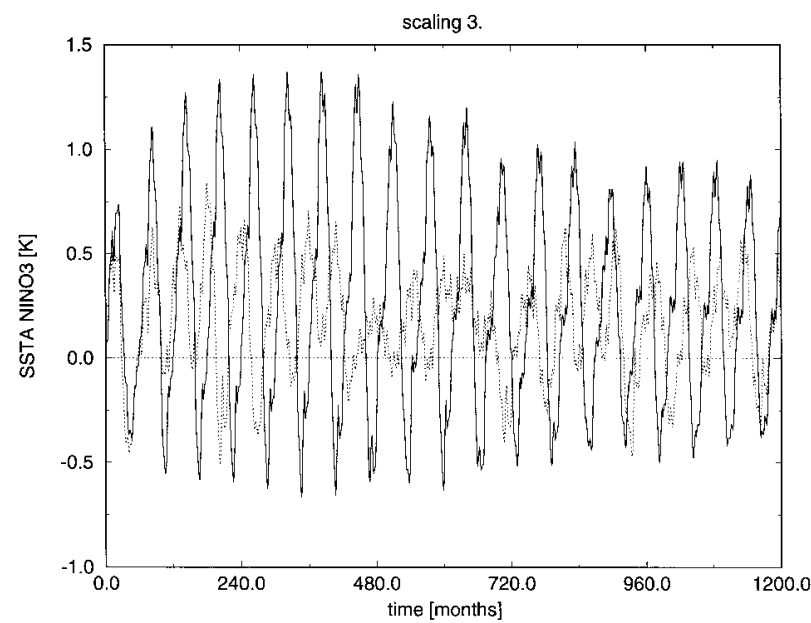

FIG. 20. Time series of eastern equatorial Pacific SST anomalies $\left({ }^{\circ} \mathrm{C}\right)$ in the Niño-3 region as simulated by the hybrid coupled model when forced by the wind stress changes associated with the decadal POP mode (dashed lines). The unperturbed control run with the HCM is shown for reference as a solid line in all three panels. (a) The cadal mode is a source of ENSO irregularity, but a simple modulation of the ENSO amplitude, as expected from "delayed action oscillator" theory, was not observed in the HCM experiments. Although stochastic forcing was not considered in the HCM experiments, the interactions between the decadal mode and the ENSO cycle are not straightforward. We therefore expect that it will be very difficult to explore the nature of this interaction in the real world.

The atmospheric changes associated with the trend in SST are not consistent with the changes observed during the 1990s. While the trends in the wind stress indicate a strengthening of the trade winds, a weakening of the trade winds was observed during the 1990s. Thus, our results are in conflict with those presented by Trenberth and Hoar (1996), who claim that the anomalous 1990s are most likely an expression of greenhouse warming. Although, the trend in SST seems not to be responsible for the anomalous 1990s, its analysis revealed some interesting results. The SST trend is rather strong and significant in the tropical Indian Ocean and western tropical Pacific, which are the warm pool regions. Consistent with a warming of the warm pool and enhanced tropical convection, the large-scale atmospheric circulation intensifies. It is important that these changes in the atmospheric circulation can feedback onto the SST. Thus, if the trend is associated with greenhouse warming, the latter will exhibit considerable spatial variations in the SST warming pattern not only due to the changes in the ocean circulation itself but also due to the anomalous fluxes resulting from the anomalous atmospheric circulation. The cooling of the North Pacific, for instance, is entirely consistent with this picture. Enhanced tropical convection will lead to a stronger Aleutian low and subsequently to cooler SSTs due to anomalous Ekman heat transport, anomalous heat loss of the ocean, and enhanced mixing. It will then eventually depend on the relative roles of the direct greenhouse warming and the dynamical feedbacks by the atmosphere whether there will be a net cooling or warming.

Likewise, the equatorial Pacific might be affected as well by the dynamical feedbacks of the atmosphere. We have shown that the trade winds intensify in both the observations and the atmosphere model data. The eastern and central equatorial Pacific will have the tendency to cool, while the western Pacific might slightly warm in response to the stronger trades. Furthermore, unstable air-sea interactions similar to those involved in the generation of ENSO might further amplify this tendency (e.g., Bjerknes 1969; Dijkstra and Neelin 1995). Inter-

$\leftarrow$

strength of the forcing corresponds to a two-standard deviation change in the decadal POP mode. (b) The strength of the forcing corresponds to a two-and-half standard deviation change in the decadal POP mode. (c) The strength of the forcing corresponds to a three-standard deviation change in the decadal POP mode. 
estingly, the SST trend pattern exhibits a relative minimum in the eastern and central equatorial Pacific, which indicates that this is indeed happening.

Overall, our results suggest that other phenomena than ENSO are going on in the tropical climate system. ENSO is certainly the strongest fluctuation on interannual timescales, but the decadal variability cannot be described exclusively as a decadal modulation of ENSO. There appears to be a decadal mode of variability that is independent of ENSO, and this decadal mode dominated the 1990s. It is unclear what the impact of the decadal mode on ENSO is, but our hybrid coupled model results suggest that the decadal mode is a source for the irregularity of ENSO and therefore important to ENSO predictability. Most ENSO prediction models failed to predict the conditions in the tropical Pacific after 1991 (e.g., Ji et al. 1996). It is still an open question why the prediction models failed. One possible reason might be that anomaly models are not able to capture the low-frequency modulations that arise from the decadal mode. We have the hope that more complete models will be able to do a better job in predicting the 1990s. The anomalous 1990s provide therefore a good testbed for the development of coupled models that are used in ENSO forecasting.

Acknowledgments. We are grateful to Dr. T. J. Crowley for his input to this paper. We like to thank Dr. Andreas Villwock for assistance with the data handling and Mr. A. Timmermann for many fruitful discussions. We would like to thank the British meteorological office (UKMO) and the National Centers for Environmental Prediction for providing the SST datasets and the Climate Modeling Division at the Max-Planck-Institut für Meteorologie for providing the AGCM results. This work was supported by the DICE project of the European Union under Grant EV5V-CI94-0538, the project Klimavariabilität und Signalanalyse of the Bundesministerium für Forschung und Technologie under Grant 07VKV01/1, and the NOAA Consortium.

\section{REFERENCES}

Barnett T. P., 1977: An attempt to verify some theories of El Niño. J. Phys. Oceanogr., 7, 633-647.

, 1991: The interaction of multiple time scales in the tropical climate system. J. Climate, 4, 269-285.

- M. Latif, N. E. Graham, M. Flügel, S. Pazan, and W. White, 1993: ENSO and ENSO-related predictability. Part I: Prediction of equatorial Pacific sea surface temperature with a hybrid coupled ocean-atmosphere model. J. Climate, 6, 1545-1566.

Bjerknes, J., 1969: Atmospheric teleconnections from the equatorial Pacific. Mon. Wea. Rev., 97, 163-172.

Bottomley, M., C. K. Folland, J. Hsiung, R. E. Newell, and D. E. Parker, 1990: Global Ocean Surface Temperaure Atlas (GOSTA). A joint project of the Meteorological Office and the Department of Earth, Atmospheric and Planetary Sciences, Massachusetts Institute of Technology, Funded by the United Kingdom Department of the Environment and the United States Navy, HMSO, London, United Kingdom.
Cardone, V. J., J. G. Greenwood, and M. A. Cane, 1990: On trends in historical marine wind data. J. Climate, 3, 113-127.

Cayan, D., 1992: Latent and sensible heat flux anomalies over the northern oceans: The connection to monthly atmospheric forcing. J. Climate, 5, 354-369.

da Silva, A. M., C. C. Young, and S. Levitus, 1994: Algorithms and Procedures. Vol. 1, Atlas of Surface Marine Data 1994. Dept. of Commerce, 83 pp. [Available from NOCD/NESDIS, E/OC21, Washington, DC 20235.]

Dijkstra, H. A., and J. D. Neelin, 1995: Ocean-atmosphere interaction and tropical climatology. Part II: Why the Pacific cold tongue is in the east. J. Climate, 8, 1343-1359.

DKRZ, 1992: The ECHAM-3 atmospheric general circulation model. Tech. Rep. 6, 184 pp. [Available from DKRZ, Bundesstr. 55, D-20146 Hamburg, Germany.]

Dunbar, R. G., G. W. Wellington, W. W. Colgan, and P. W. Glynn, 1994: Eastern Pacific temperature since 1600 A.D.: The $\delta^{18} \mathrm{O}$ record of climate variability in Galapagos corals. Paleoceanography, 9, 291-315.

Flügel, M., 1994: Untersuchungen zu Mechanismus und Vorhersagbarkeit von ENSO mit einem vereinfachten gekoppelten OzeanAtmosphäre-Modell. Ph.D. thesis, 67 pp. [Available from MaxPlanck-Institut für Meteorologie, Bundesstr. 55, D-20146 Hamburg, Germany.]

Ghil, M., and R. Vautard, 1991: Interdecadal oscillations and the warming trend in global temperature time series. Nature, 350, $324-327$.

Goddard, L., and N. E. Graham, 1997: El Niño in the 1990s. J. Geophys. Res., in press.

Graham, N. E., 1994: Decadal-scale climate variability in the tropical and North Pacific during the 1970's and 1980's: Observations and model results. Climate Dyn., 10, 135-162.

_ 1995: Simulation of recent global temperature trends. Science, 267, 666-671.

Gu, D., and S. G. H. Philander, 1997: Interdecadal climate fluctuations that depend on exchanges between the tropics and the extratropics. Science, 275, 805-807.

Hasselmann, K., 1988: PIPs and POPs: The reduction of complex dynamical systems using Principal Interaction and Principal Oscillation Patterns. J. Geophys. Res., 93D, 11 015-11 021.

Ji, M., A. Leetmaa, and V. E. Kousky, 1996: Coupled model forecasts of ENSO during the 1980s and 1990s at the National Meteorological Center. J. Climate, 9, 3105-3120.

Kawamura, R., 1994: A rotated EOF analysis of global sea surface temperature variability with interannual and interdecadal scales. J. Phys. Oceanogr., 24, 707-715.

Kleeman, R., R. Colman, N. R. Smith, and S. B. Power, 1996: A recent change in the mean state of the Pacific Ocean: Observational evidence, atmospheric response and implications for coupled modeling. J. Geophys. Res., 101, 20 483-20 499.

Latif, M., and T. P. Barnett, 1994: Causes of decdal climate variability over the North Pacific and North America. Science, 266, 634637.

— Pacific and North America: Dynamics and predictability. J. Climate, 9, 2407-2423.

Lau, N. C., 1985: Modeling the seasonal dependence of the atmospheric response to observed El Niños in 1962-76. Mon. Wea. Rev., 113, 1970-1996.

Linsley, B. K., R. B. Dunbar, G. M. Wellington, and D. A. Mucciarone, 1994: A coral-based reconstruction of interpropical convergence zone variability over central America since 1707. J. Geophys. Res., 99, 9977-9994.

Liu, Z., S. G. H. Philander, and R. C. Pacanowski, 1994: A GCM study of tropical-subtropical upper-ocean water exchange. $J$. Phys. Oceanogr., 24, 2606-2623.

Mann, M. E., and J. Park, 1994: Global-scale modes of surface temperature variability on interannual and century timescales. $J$. Geophys. Res., 99, 25 819-25833.

McCreary, J. P., and P. Lu, 1994: Interaction between the subtropical 
and equatorial ocean circulation: The subtropical cell. J. Phys. Oceanogr., 24, 466-497.

Meehl, G. A., and W. M. Washington, 1996: Pacific region climate change. Nature, 382, 56-60.

Miller, A. J., D. C. Cayan, T. P. Barnett, N. E. Graham, and J. M. Oberhuber, 1994: Interdecadal variability of the Pacific Ocean: Model response to observed heat flux and wind stress anomalies. Climate Dyn., 9, 287-302.

Murphy, J. M., and J. F. B. Mitchell, 1995: Transient response of the Hadley Centre coupled ocean-atmosphere model to increasing carbon dioxide. Part II: Spatial and temporal structure of response. J. Climate, 8, 57-80.

Namias, J., 1963: Large-scale air-sea interactions over the North Pacific from summer 1962 through the subsequent winter. J. Geophys. Res., 68, 6171-6186.

Parker, D. E., and C. K. Folland, 1991: Worldwide surface temperature trends since the mid-19th century. Greenhouse-Gas-Induced Climatic Change: A Critical Appraisal of Simulations and Observations, M. E. Schlesinger, Ed., Elsevier, 173-193.

,-- A. Bevan, M. N. Ward, M. Jackson, and K. Maskell, 1995: Marine surface data for analysis of climatic fluctuations on interannual and to century time scales. Natural Climate Variability on Decade-to-Century Time Scales, D. G. Martinson, K. Bryan, M. Ghil, M. M. Hall, T. R. Karl, E. S. Sarachik, S. Sorooshian, and L. D. Talley, Ed., National Academy Press, 241250.

Posmentier, E. S., M. A. Cane, and S. E. Zebiak, 1989: Tropical Pacific climate trends since 1960. J. Climate, 2, 731-736.

Quinn, T. M., F. W. Taylor, and T. J. Crowley, 1993: A 173 year stable isotope record from New Caledonia. Quat. Sci. Rev., 12, 407418.

Rasmusson, E. M., and T. H. Carpenter, 1982: Variations in tropical sea surface temperature and surface winds associated with the Southern Oscillation/El Niño. Mon. Wea. Rev., 110, 354-384.
Reynolds, R. W., and T. M. Smith, 1994: Improved global sea surface temperature analyses using optimum interpolation. J. Climate, 7, 929-48.

Robertson, A. W., 1996: Interdecadal variability over the North Pacific in multi-century climate simulation. Climate Dyn., 12, 227241.

Roeckner, E., and Coauthors, 1992: Simualtion of present-day climate with the ECHAM model: Impact of model physics and resolution. Max-Planck-Institut für Meteorologie Rep. 93, 171 pp. [Available from Max-Planck-Institut für Meteorologie, Bundesstr. 55, D-20146 Hamburg, Germany.]

Stendel, M., and L. Bengtsson, 1996: Monitoring the temperature of the troposphere by means of a general circulation model. MaxPlanck-Institut für Meteorologie Rep. 186, 26 pp. [Available from Max-Planck-Institut für Meteorologie, Bundesstr. 55, D-20146 Hamburg, Germany.]

Trenberth, K. E., and J. W. Hurrell, 1994: Decadal atmosphere-ocean variations in the Pacific. Climate Dyn., 9, 303-319.

— cillation event: Longest on record. Geophys. Res. Lett., 23, 5760 .

von Storch, H., G. Bürger, R. Schnur, and J.-S. von Storch, 1995: Principal Oscillation Patterns: A review. J. Climate, 8, 377-400.

Wallace, J. M., C. Smith, and Q. Jiang, 1990: Spatial patterns of atmosphere-ocean interaction in the northern winter. J. Climate, 3, 990-998.

_ , Y. Zhang, and L. Bajuk, 1996: Interpretation of interdecadal trends in Northern Hemisphere surface air temperature. J. Climate, 9, 249-259.

Weare, B., A. Navato, and R. F. Newell, 1976: Empirical orthogonal analysis of Pacific Ocean sea surface tempertures. J. Phys. Oceanogr., 6, 671-678.

Zhang, Y., J. M. Wallace, and D. S. Battisti, 1997: ENSO-like interdecadal variability: 1900-93. J. Climate, 10, 1004-1020. 